Supporting Information

\title{
Can Donor Ligands Make Pd(OAc) 2 a Stronger Oxidant? Access to Elusive Palladium(II) Reduction Potentials and Effects of Ancillary Ligands via Palladium(II)/Hydroquinone Redox Equilibria \\ David L. Bruns ${ }^{\dagger}$, Djamaladdin G. Musaev ${ }^{\ddagger}$ and Shannon S. Stahl*† \\ ${ }^{\dagger}$ Department of Chemistry, University of Wisconsin-Madison, 1101 University Avenue, Madison, WI, 53706 \\ ${ }^{\ddagger}$ Cherry L. Emerson Center for Scientific Computation and Department of Chemistry, Emory University, Atlanta, Georgia 30322, United States \\ email: stahl@,chem.wisc.edu
}

\section{Table of Contents}

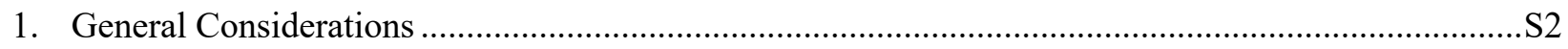

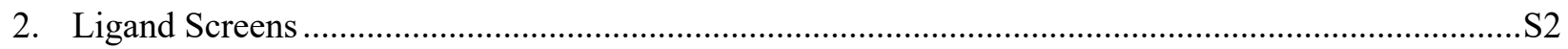

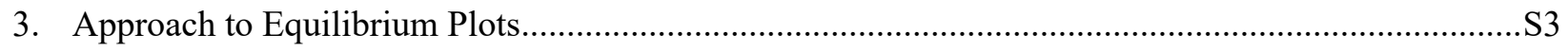

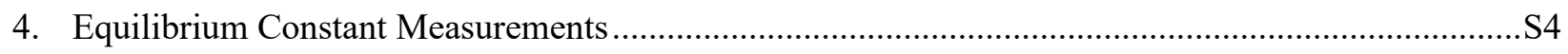

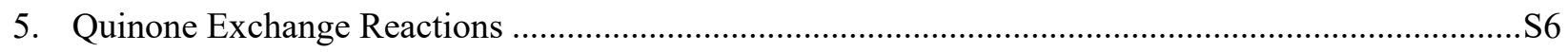

6. Quinone/hydroquinone Reduction Potential Determination by Open Circuit Potential (OCP)

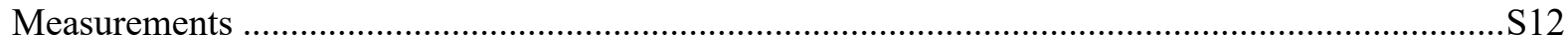

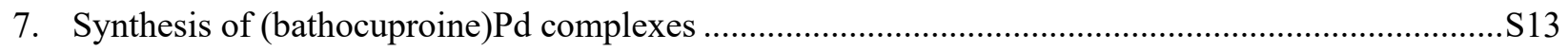

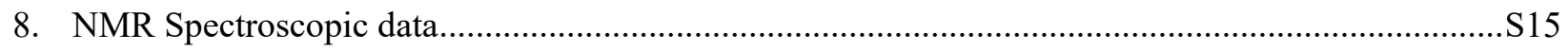

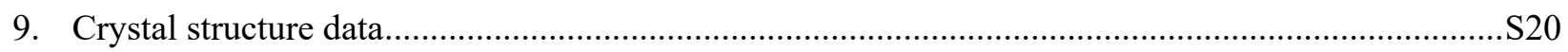

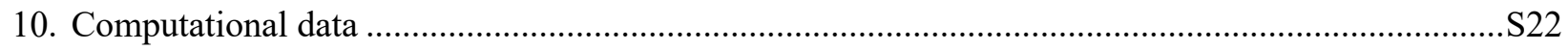

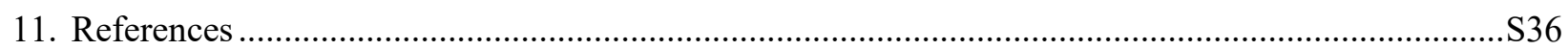




\section{General Considerations}

All manipulations were carried out in a glovebox or using standard Schlenk line technique unless specified otherwise. All chemicals and solvents were purchased from commercially available sources. Substituted benzoquinones were purified by sublimation. 1,4-dioxane was distilled from sodium benzophenone ketyl radical and stored under inert atmosphere. Chloroform and D-chloroform were dried over calcium hydride and stored under inert atmosphere. Palladium acetate was purchased from Sigma-Aldrich and used without further purification, although the purity of the $\mathrm{Pd}(\mathrm{OAc})_{2}$ was confirmed by ${ }^{1} \mathrm{H}$ NMR spectroscopic analysis because $\mathrm{Pd}(\mathrm{OAc})_{2}$ is occasionally contaminated with $\mathrm{NO}_{2}$ substituting an acetate ligand. ${ }^{1}$. Palladium dimer $\left[\mathrm{Pd}^{\mathrm{I}}(\mu-\mathrm{DAF})(\mathrm{OAc})\right]_{2}$ was prepared according to literature procedure. ${ }^{2}$ All NMR spectra were obtained on Bruker-Avance 400, 500, or $600 \mathrm{MHz}$ spectrometers. Attenuated total reflectance FTIR (ATR-FTIR) data were collected on a Bruker Tensor 27 on a Pike Technologies diamond ATR stage.

\section{Ligand Screens}

Ligand Screen for Conversion of ${ }^{t} \mathrm{BuH}_{2}{ }_{2} \mathrm{BQ}$ with $\mathrm{Pd}(\mathrm{OAc})_{2} / \mathrm{L}$ in dioxane $/ \mathrm{d}_{4}-\mathrm{AcOD}$

Stock solutions of ligands were prepared in dichloromethane such that a $100 \mu \mathrm{L}$ aliquot contained 0.008 mmol of ligand $\left(0.016 \mathrm{mmol}\right.$ for pyridine). A stock solution of $\mathrm{Pd}(\mathrm{OAc})_{2}(18.2 \mathrm{mg}, 0.081 \mathrm{mmol})$ in dichloromethane $(1.0 \mathrm{~mL})$ was prepared. $100 \mu \mathrm{L}$ of ligand stock solution and $100 \mu \mathrm{L}$ of $\mathrm{Pd}(\mathrm{OAc})_{2}$ stock solution were transferred to scintillation vials, the dichloromethane was removed in vacuo, and the vials were transferred to a glovebox. A stock solution of ${ }^{t} \mathrm{BuH}_{2} \mathrm{BQ}(67.3 \mathrm{mg}, 0.405 \mathrm{mmol})$ and internal standard (1,3,5-trimethoxybenzene; $22.7 \mathrm{mg}, 0.134 \mathrm{mmol})$ in dioxane:AcOD- $d_{4}$ mixture $(3: 1 \mathrm{vol}: \mathrm{vol}, 10.0 \mathrm{~mL})$ was prepared. Into each of the vials containing $\mathrm{Pd}(\mathrm{OAc})_{2} / \mathrm{L}$ was added $600 \mu \mathrm{L}$ of the ${ }^{t} \mathrm{BuH}_{2} \mathrm{BQ}$ solution. The solutions were stirred for approximately $1 \mathrm{~h}$ before being transferred to NMR tubes and were allowed to stand for $24 \mathrm{~h}$ before ${ }^{1} \mathrm{H}$ NMR spectra were collected ( 8 scans, 2 dummy scans, $16 \mathrm{~s}$ T1 relaxation delay). The ${ }^{t} \mathrm{Bu}$ peak of remaining ${ }^{t} \mathrm{BuH}_{2} \mathrm{BQ}$ was integrated relative to internal standard to quantify conversion.

Ligand Screen for Conversion of ${ }^{t} \mathrm{BuH}_{2} \mathrm{BQ}$ with $\mathrm{Pd}(\mathrm{OAc})_{2} / \mathrm{L}$ in $\mathrm{CDCl}_{3} / \mathrm{d}_{4}-\mathrm{AcOD}$

Stock solutions of ligands $(0.06 \mathrm{mmol}$ in $1000 \mu \mathrm{L}$ dichloromethane $),{ }^{t} \mathrm{BuH}_{2} \mathrm{BQ}(0.06 \mathrm{mmol}$ in $1000 \mu \mathrm{L}$ inhibitor-free THF), $\mathrm{Pd}(\mathrm{OAc})_{2}(0.09 \mathrm{mmol}$ in $1500 \mu \mathrm{L}$ dichloromethane $)$ and methyl-3,5-dinitrobenzoate internal standard $\left(0.18 \mathrm{mmol}\right.$ in the same $1500 \mu \mathrm{L}$ solution as $\left.\mathrm{Pd}(\mathrm{OAc})_{2}\right)$ were prepared. $\mathrm{The}^{t} \mathrm{BuH}_{2} \mathrm{BQ}$ stock solution $(100 \mu \mathrm{L})$ was added to a scintillation vial and the solvent was removed under reduced pressure. Into separate vials were added $100 \mu \mathrm{L}$ of the ligand stock solutions and $100 \mu \mathrm{L}$ of the $\mathrm{Pd}(\mathrm{OAc})_{2} /$ internal standard stock solutions and the solvent was removed in vacuo. The vials were then transferred into a glovebox and the solid mixtures of $\mathrm{Pd}(\mathrm{OAc})_{2} /$ ligand/internal standard were dissolved in $600 \mu \mathrm{L}$ of a $1.5 \mathrm{M}$ solution of AcOD- $d_{4}$ in $\mathrm{CDCl}_{3}$. Each of these solutions was transferred to the vials containing ${ }^{t} \mathrm{BuH}_{2} \mathrm{BQ}$ and stirred until homogeneous, after which they were transferred to NMR tubes, capped, and allowed to stand at ambient temperature in the glovebox for $16 \mathrm{~h}$ before collecting ${ }^{1} \mathrm{H}$ NMR spectra. The ${ }^{t} \mathrm{Bu}$ peak of remaining ${ }^{t} \mathrm{BuH}_{2} \mathrm{BQ}$ was integrated relative to internal standard to quantify conversion. 


\section{Approach to Equilibrium Plots}

(DAF)Pd(OAc) $)_{2} /\left[\mathbf{P d}^{\mathrm{I}}(\boldsymbol{\mu}-\mathrm{DAF})(\mathbf{O A c})\right]_{2}$ (See Figure 3 in the manuscript)

For "Forward" Direction:

In a glove box, a $2.0 \mathrm{~mL}$ stock solution of $\mathrm{Pd}(\mathrm{OAc})_{2}(6.1 \mathrm{mg}, 0.027 \mathrm{mmol}), 4,5$-diazfluorenone (DAF, 4.9 $\mathrm{mg}, 0.027 \mathrm{mmol}$ ), and internal standard (3,5-dinitromethylbenzoate; $6.1 \mathrm{mg}, 0.027 \mathrm{mmol}$ ) in $2.0 \mathrm{~mL}$ of a 3:1 mixture (vol:vol) of dioxane:AcOD- $d_{4}$ was prepared. A separate stock solution of ${ }^{t} \mathrm{BuH}_{2} \mathrm{BQ},(13.5 \mathrm{mg}$, $0.081 \mathrm{mmol}$, in $1.0 \mathrm{~mL}$ of dichloromethane) was prepared, and $50 \mu \mathrm{l}$ of this solution was transferred to a 6 $\mathrm{mL}$ scintillation vial. The dichloromethane was removed in vacuo, the ${ }^{t} \mathrm{BuH}_{2} \mathrm{BQ}$ was dissolved in a $600 \mu \mathrm{L}$ portion of the $\mathrm{Pd}(\mathrm{OAc})_{2} / \mathrm{DAF} /$ internal standard stock solution and quickly transferred to an NMR tube. The tube was capped, removed from the glove box, and frozen in liquid nitrogen. The sample was kept frozen until data collection commenced. ${ }^{1} \mathrm{H}$ NMR spectra were collected every $15 \mathrm{~min}$ for the first $10 \mathrm{~h}$ and every $2.5 \mathrm{~h}$ for the remaining $14 \mathrm{~h}$ of the experiment (T1 relaxation delay of $21 \mathrm{~s}$.). The DAF ligand signals were integrated relative to internal standard to quantify $\left[\mathrm{Pd}^{\mathrm{I}}(\mu-\mathrm{DAF})(\mathrm{OAc})\right]_{2}$ and the tert-butyl signal of ${ }^{t} \mathrm{BuH}_{2} \mathrm{BQ}$ and ${ }^{t} \mathrm{BuBQ}$ were integrated to quantify quinone concentration. Equilibrium constants were calculated according to eq 2 in the main text.

For "Reverse" direction:

In a glove box, a stock solution of $\left[\mathrm{Pd}^{\mathrm{I}}(\mu-\mathrm{DAF})(\mathrm{OAc})\right]_{2}(7.0 \mathrm{mg}, 0.010 \mathrm{mmol})$ and internal standard (3,5dinitromethylbenzoate; $4.6 \mathrm{mg}, 0.020 \mathrm{mmol})$ in $1.5 \mathrm{~mL}$ of dioxane:AcOD- $d_{4}$ was prepared. A separate stock solution of ${ }^{t} \mathrm{BuBQ}(13.5 \mathrm{mg}, 0.081 \mathrm{mmol}$, in $1.0 \mathrm{~mL}$ of dichloromethane) was prepared, and $50 \mu \mathrm{l}$ of this solution was transferred to a $6 \mathrm{~mL}$ scintillation vial before the dichloromethane was removed in vacuo. The ${ }^{t} \mathrm{BuBQ}$ was dissolved in a $600 \mu \mathrm{L}$ portion of the $\left[\mathrm{Pd}^{\mathrm{I}}(\mu-\mathrm{DAF})(\mathrm{OAc})\right]_{2} /$ internal standard stock solution and quickly transferred to an NMR tube, which was capped, removed from the purge box, and frozen in liquid nitrogen. The sample was kept frozen until data collection commenced. ${ }^{1} \mathrm{H}$ NMR Spectra were collected every $5 \mathrm{~min}$ for the first $10 \mathrm{~h}$ and approximately every $2.5 \mathrm{~h}$ for the remaining $14 \mathrm{~h}$ of the experiment (T1 relaxation delay of $21 \mathrm{~s}$ ).

(Bathocuproine)Pd(OAc) $)_{2} /($ bathocuproine)Pd(RBQ) (See Figure 4 in the manuscript) For "Forward" Direction:

In a glovebox, a stock solution of $(\mathrm{bc}) \mathrm{Pd}(\mathrm{OAc})_{2}(7.3 \mathrm{mg}, 0.12 \mathrm{mmol})$ in $1.0 \mathrm{~mL}$ of $1.5 \mathrm{M}$ AcOD- $d_{4}$ in $\mathrm{CDCl}_{3}$ was prepared. A separate solution of ${ }^{t} \mathrm{BuH}_{2} \mathrm{BQ}(8.3 \mathrm{mg}, 0.05 \mathrm{mmol})$ and methyl-3,5-dinitrobenzoate internal standard $(11.3 \mathrm{mg}, 0.05 \mathrm{mmol})$ in $1.0 \mathrm{~mL}$ of $1.5 \mathrm{M} \mathrm{AcOD}-d_{4}$ in $\mathrm{CDCl}_{3}$ was prepared. A $400 \mu \mathrm{L}$ aliquot of the $(\mathrm{bc}) \mathrm{Pd}(\mathrm{OAc})_{2}$ solution was injected to an NMR tube and capped with a septum cap. Just before the sample was inserted into the NMR spectrometer, $100 \mu \mathrm{L}$ of the ${ }^{t} \mathrm{BuH}_{2} \mathrm{BQ} /$ internal standard solution was injected through the septum cap and shaken well to ensure good mixing. The NMR tube was inserted into the spectrometer and data collection was commenced (spectra collected every 5 min with $4 \mathrm{~s}$ T1 relaxation delay). The time between the injection and the first spectrum was recorded. To quantify concentration, the tert-butyl peaks of the (bc) $\mathrm{Pd}\left({ }^{t} \mathrm{BuBQ}\right)$ and ${ }^{t} \mathrm{BuH}_{2} \mathrm{BQ}$ were integrated relative to internal standard.

For "Reverse" direction:

A stock solution of methyl-3,5-dinitrobenzoate internal standard $(12.2 \mathrm{mg}, 0.054 \mathrm{mmol})$ in $5.0 \mathrm{~mL}$ of $\mathrm{CDCl}_{3}$ was prepared. A separate stock solution of (bc)Pd( $\left(\eta^{2}-{ }^{t} \mathrm{BuBQ}\right)(7.1 \mathrm{mg}, 0.011 \mathrm{mmol})$ in $1.0 \mathrm{~mL}$ of the internal standard stock solution was prepared. Into an NMR tube was injected $550 \mu \mathrm{L}$ of the (bc) $\operatorname{Pd}\left(\eta^{2}-{ }^{t} \mathrm{BuBQ}\right)$ solution, which was capped with a septum cap and taken to the NMR spectrometer. Just before the sample was inserted into the spectrometer, $51 \mu \mathrm{L}$ of AcOD- $d_{4}$ was injected. The tube was shaken to ensure good mixing and inserted into the spectrometer before data collection was commenced (spectra collected every 5 min with $4 \mathrm{~s}$ T1 relaxation delay). The time between the injection and the first spectrum was recorded. 


\section{Equilibrium Constant Measurements}

\section{(DAF)Pd(OAc) $)_{2} /\left[\mathbf{P d}^{\mathrm{I}}(\boldsymbol{\mu}-\mathrm{DAF})(\mathrm{OAc})\right]_{2}$}

Stock solutions of $\mathrm{Pd}(\mathrm{OAc})_{2}(13.6 \mathrm{mg}, 0.606 \mathrm{mmol}$ in $750 \mu \mathrm{L}$ of dichloromethane), $\mathrm{DAF}$ (14.8 mg, 0.081 $\mathrm{mmol}$ in $1.0 \mathrm{~mL}$ of dichloromethane), and internal standard (methyl 3,5-dinitrobenzoate; $18.3 \mathrm{mg}, 0.081$ mmol in $1.0 \mathrm{~mL}$ of dichloromethane) were prepared. Into 5 separate $6 \mathrm{~mL}$ scintillation vials, $100 \mu \mathrm{L}$ of each of the stock solutions were apportioned and the dichloromethane was removed in vacuo and transferred to a glove box. Stock solutions of the substituted hydroquinones (2,6-dimethylhydroquinone, 2tertbutylhydroquinone, 2-methylhydroquinone, hydroquinone, and 2-chlorohydroquinone) were prepared $(0.081 \mathrm{mmol}$ in $1.0 \mathrm{~mL}$ dichloromethane). Into 5 separate $6 \mathrm{~mL}$ scintillation vials, $100 \mu \mathrm{L}$ of each of the solutions were apportioned before the dichloromethane was removed in vacuo and transferred to a glove box. The $\mathrm{Pd}(\mathrm{OAc})_{2} / \mathrm{DAF} /$ internal standard mixture was dissolved in $600 \mu \mathrm{L}$ of dioxane:AcOD- $d_{4}$. The substituted hydroquinones were then dissolved in the $\mathrm{Pd}(\mathrm{OAc})_{2} / \mathrm{DAF} /$ internal standard solution and then transferred to an NMR tube and allowed to stand for $24 \mathrm{~h}$ in the glovebox at ambient temperature before NMR spectra were collected. The DAF ligand signals were integrated to quantify $\left[\operatorname{Pd}^{\mathrm{I}}(\mu-\mathrm{DAF})(\mathrm{OAc})\right]_{2}$ and the tert-butyl signal of ${ }^{t} \mathrm{BuH}_{2} \mathrm{BQ}$ and ${ }^{t} \mathrm{BuBQ}$ were integrated to quantify quinone concentration. Equilibrium constants were calculated according to eq 2 in the main text. Error analysis was conducted by means of standard propagation of error calculations. For $x=\log (a)$ : $\mathrm{S}_{\mathrm{x}}=0.434\left[\mathrm{~S}_{a} / a\right]$, where $a$ is random variable, $\mathrm{S}_{\mathrm{x}}$ $=$ standard deviation of $x, \mathrm{~S}_{a}=$ standard deviation of $a$.

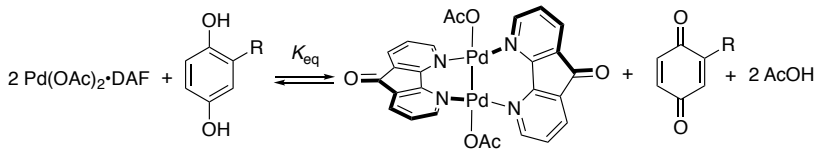

Table S1: Determination of equilibrium constants for eq S1.

\begin{tabular}{|c|c|c|c|c|c|c|}
\hline Hydroquinone & $\begin{array}{l}\text { Equivalents } \mathrm{RH}_{2} \mathrm{BQ} \\
\text { (relative to total [Pd]) }\end{array}$ & $K_{\text {eq }}$ & $K_{\text {eq }}$ average & std dev & $\log \left(K_{\text {eq }}\right)$ & error \\
\hline 2,6- $\mathrm{Me}_{2} \mathrm{H}_{2} \mathrm{BQ}$ & 0.5 & 8292.2 & \multirow{2}{*}{7241.5} & \multirow{2}{*}{1486.0} & \multirow{2}{*}{3.9} & \multirow{2}{*}{0.1} \\
\hline 2,6- $\mathrm{Me}_{2} \mathrm{H}_{2} \mathrm{BQ}$ & 3.0 & 6190.7 & & & & \\
\hline${ }^{t} \mathrm{BuH}_{2} \mathrm{BQ}$ & 0.5 & 305.9 & \multirow{2}{*}{305.2} & \multirow{2}{*}{0.9} & \multirow[b]{2}{*}{2.5} & \multirow[b]{2}{*}{0.001} \\
\hline${ }^{t} \mathrm{BuH}_{2} \mathrm{BQ}$ & 3.0 & 304.6 & & & & \\
\hline $\mathrm{MeH}_{2} \mathrm{BQ}$ & 0.5 & 91.7 & \multirow{2}{*}{90.0} & \multirow{2}{*}{2.4} & \multirow{2}{*}{2.0} & \multirow{2}{*}{0.01} \\
\hline $\mathrm{MeH}_{2} \mathrm{BQ}$ & 3.0 & 88.3 & & & & \\
\hline $\mathrm{H}_{2} \mathrm{BQ}$ & 0.5 & 1.0 & \multirow{2}{*}{1.5} & \multirow{2}{*}{0.8} & \multirow{2}{*}{0.2} & \multirow{2}{*}{0.2} \\
\hline $\mathrm{H}_{2} \mathrm{BQ}$ & 3.0 & 2.1 & & & & \\
\hline $\mathrm{ClH}_{2} \mathrm{BQ}$ & 0.5 & 0.1 & \multirow{2}{*}{0.4} & \multirow{2}{*}{0.4} & \multirow{2}{*}{-0.5} & \multirow{2}{*}{0.4} \\
\hline $\mathrm{ClH}_{2} \mathrm{BQ}$ & 3.0 & 0.6 & & & & \\
\hline
\end{tabular}




\section{(bc) $\operatorname{Pd}(\mathrm{OAc})_{2} /(\mathbf{b c}) \operatorname{Pd}\left(\eta^{2}-\mathrm{BQ}\right.$}

A stock solution of $\mathrm{Pd}(\mathrm{OAc})_{2}(33.7 \mathrm{mg}, 0.15 \mathrm{mmol})$, bathocuproine $(54.1 \mathrm{mg}, 0.15 \mathrm{mmol})$, and methyl3,5 ,-dinitrobenzoate internal standard $(67.84 \mathrm{mg}, 0.30 \mathrm{mmol})$ in $15 \mathrm{~mL}$ of a $1.5 \mathrm{M}$ solution of AcOD-d $\mathrm{d}_{4}$ in $\mathrm{CDCl}_{3}$ was prepared in a glovebox. A separate stock solution of ${ }^{t} \mathrm{BuH}_{2} \mathrm{BQ}(14.9 \mathrm{mg}, 0.09 \mathrm{mmol})$ was prepared in $2.0 \mathrm{~mL}$ of dichloromethane, and with an airtight Hamilton syringe $50 \mu \mathrm{L}, 100 \mu \mathrm{L}, 200 \mu \mathrm{L}, 300$ $\mu \mathrm{L}$, and $400 \mu \mathrm{L}$ of this solution were transferred into 5 separate $4 \mathrm{~mL}$ vials. The dichloromethane was removed in vacuo, and the vials were moved to the glovebox. To each vial of ${ }^{t} \mathrm{BuH}_{2} \mathrm{BQ}$ was added $600 \mu \mathrm{L}$ of the $\mathrm{Pd}(\mathrm{OAc})_{2} / \mathrm{bc} /$ internal standard solution. Once the ${ }^{t} \mathrm{BuH}_{2} \mathrm{BQ}$ dissolved, the solution was transferred to and NMR tube and allowed to stand at room temperature for $16 \mathrm{~h}$ in the glove box before ${ }^{1} \mathrm{H}$ NMR spectra were recorded. An analogous procedure was repeated for $\mathrm{MeH}_{2} \mathrm{BQ}, \mathrm{H}_{2} \mathrm{BQ}$, and $\mathrm{ClH}_{2} \mathrm{BQ}$. Equilibrium constants were calculated according to eq 3 in the main text. Error analysis was conducted by means of standard propagation of error calculations. For $x=\log (a)$ : $\mathrm{S}_{\mathrm{x}}=0.434\left[\mathrm{~S}_{a} / a\right]$, where $a$ is random variable, $\mathrm{S}_{\mathrm{x}}$ $=$ standard deviation of $x, \mathrm{~S}_{a}=$ standard deviation of $a$.

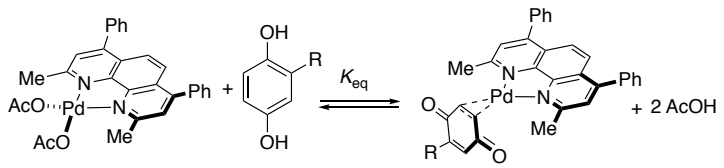

Table S2. Determination of equilibrium constants for eq S2.

\begin{tabular}{|c|c|c|c|c|c|c|}
\hline Hydroquinone & $\begin{array}{l}\text { Equivalents } \mathrm{RH}_{2} \mathrm{BQ} \\
\text { (relative to total [Pd]) }\end{array}$ & $K_{\text {eq }}$ & $K_{\text {eq }}$ average & std dev & $\log \left(K_{\text {eq }}\right)$ & error \\
\hline${ }^{t} \mathrm{BuH}_{2} \mathrm{BQ}$ & 0.5 & 87.2 & \multirow{5}{*}{128.6} & \multirow{5}{*}{25.5} & \multirow{5}{*}{2.1} & \multirow{5}{*}{0.09} \\
\hline${ }^{t} \mathrm{BuH}_{2} \mathrm{BQ}$ & 1.0 & 149.9 & & & & \\
\hline${ }^{t} \mathrm{BuH}_{2} \mathrm{BQ}$ & 2.0 & 134.9 & & & & \\
\hline${ }^{t} \mathrm{BuH}_{2} \mathrm{BQ}$ & 3.0 & 123.4 & & & & \\
\hline${ }^{t} \mathrm{BuH}_{2} \mathrm{BQ}$ & 4.0 & 147.7 & & & & \\
\hline
\end{tabular}

\begin{tabular}{|c|c|c|c|c|c|c|}
\hline Hydroquinone & $\begin{array}{l}\text { Equivalents } \mathrm{RH}_{2} \mathrm{BQ} \\
\text { (relative to total [Pd]) }\end{array}$ & $K_{\text {eq }}$ & $K_{\text {eq }}$ average & std dev & $\log \left(K_{\text {eq }}\right)$ & error \\
\hline $\mathrm{MeH}_{2} \mathrm{BQ}$ & 0.5 & 25.6 & \multirow{5}{*}{29.9} & \multirow{5}{*}{4.1} & \multirow{5}{*}{1.5} & \multirow{5}{*}{0.06} \\
\hline $\mathrm{MeH}_{2} \mathrm{BQ}$ & 1.0 & 26.1 & & & & \\
\hline $\mathrm{MeH}_{2} \mathrm{BQ}$ & 2.0 & 32.8 & & & & \\
\hline $\mathrm{MeH}_{2} \mathrm{BQ}$ & 3.0 & 30.0 & & & & \\
\hline $\mathrm{MeH}_{2} \mathrm{BQ}$ & 4.0 & 35.1 & & & & \\
\hline
\end{tabular}

\begin{tabular}{|c|c|c|c|c|c|c|}
\hline Hydroquinone & $\begin{array}{l}\text { Equivalents } \mathrm{RH}_{2} \mathrm{BQ} \\
\text { (relative to total }[\mathrm{Pd}] \text { ) }\end{array}$ & $K_{\text {eq }}$ & $K_{\text {eq }}$ average & std dev & $\log \left(K_{\text {eq }}\right)$ & error \\
\hline $\mathrm{H}_{2} \mathrm{BQ}$ & 0.5 & 2.3 & \multirow{5}{*}{2.8} & \multirow{5}{*}{0.3} & \multirow{5}{*}{0.4} & \multirow{5}{*}{0.05} \\
\hline $\mathrm{H}_{2} \mathrm{BQ}$ & 1.0 & 2.8 & & & & \\
\hline $\mathrm{H}_{2} \mathrm{BQ}$ & 2.0 & 3.1 & & & & \\
\hline $\mathrm{H}_{2} \mathrm{BQ}$ & 3.0 & 2.8 & & & & \\
\hline $\mathrm{H}_{2} \mathrm{BQ}$ & 4.0 & 2.8 & & & & \\
\hline
\end{tabular}

\begin{tabular}{|c|c|c|c|c|c|c|}
\hline Hydroquinone & $\begin{array}{c}\text { Equivalents } \mathrm{RH}_{2} \mathrm{BQ} \\
\text { (relative to total }[\mathrm{Pd}] \text { ) }\end{array}$ & $K_{\text {eq }}$ & \multirow{2}{*}{$K_{\text {eq }}$ average } & std dev & log $\left(K_{\text {eq }}\right)$ & error \\
\hline $\mathrm{ClH}_{2} \mathrm{BQ}$ & 0.5 & $0.0^{*}$ & & & \\
\hline $\mathrm{ClH}_{2} \mathrm{BQ}$ & 1.0 & 0.9 & \multirow{2}{*}{0.5} & \multirow{2}{*}{0.3} & \multirow{2}{*}{0.3} \\
\hline $\mathrm{ClH}_{2} \mathrm{BQ}$ & 2.0 & 0.4 & & & \\
\hline $\mathrm{ClH}_{2} \mathrm{BQ}$ & 3.0 & 0.5 & & & & \\
\hline $\mathrm{ClH}_{2} \mathrm{BQ}$ & 4.0 & 0.6 & & & & \\
\hline
\end{tabular}

*No measurable concentration of $(\mathrm{bc}) \mathrm{Pd}\left(\left(\eta^{2}-\mathrm{ClBQ}\right)\right.$ complex with only 0.5 equivalents of $\mathrm{ClH}_{2} \mathrm{BQ}$. 


\section{Quinone Exchange Reactions}

For the reaction shown in equation (S3) below: Into a two separate $4 \mathrm{~mL}$ vials, $(\mathrm{bc}) \mathrm{Pd}(\mathrm{OAc})_{2}(3.51 \mathrm{mg}$, $0.006 \mathrm{mmol}$ ) and 2- $\mathrm{MeH}_{2} \mathrm{BQ}\left(0.74 \mathrm{mg}, 0.006 \mathrm{mmol}\right.$ ) were dissolved in $500 \mu \mathrm{L}$ of $\mathrm{CDCl}_{3}$ [the $\mathrm{Pd}^{0}$ (quinone) adducts were generated in situ to avoid complications associated with their isolation, which in some cases proved challenging because of decomposition of the products on concentration]. The formation of the corresponding (bc) $\mathrm{Pd}\left(\eta^{2}-2-\mathrm{MeBQ}\right)$ adduct was allowed to proceed to completion $(\sim 20 \mathrm{~min})$ before 5 equivalents ${ }^{t} \mathrm{BuBQ}(4.93 \mathrm{mg}, 0.03 \mathrm{mmol})$ and 10 equivalents ${ }^{t} \mathrm{BuBQ}(9.85 \mathrm{mg}, 0.06 \mathrm{mmol})$ were added to each respective vial as $100 \mu \mathrm{L}$ solutions. The reactions reach equilibrium rapidly but were allowed to stand overnight before ${ }^{1} \mathrm{H}$ NMR spectra were collected at $-60{ }^{\circ} \mathrm{C},-50{ }^{\circ} \mathrm{C},-40{ }^{\circ} \mathrm{C}$, and $-30{ }^{\circ} \mathrm{C}$. Analogous procedures were followed for equations (S4) and (S5).

The exchange reactions were carried out at low temperature because exchange kinetics on the NMR time scale at room temperature caused significant broadening that precluded reliable integration. In the case of (bc)Pd( $\left.\eta^{2}-{ }^{t} \mathrm{BuBQ}\right), \mathrm{MeBQ}$ was determined to be a more convenient exchange partner, as the equilibrium exchange of BQ with (bc)Pd $\left(\eta^{2}{ }^{t} \mathrm{BuBQ}\right)$ favored $(\mathrm{bc}) \mathrm{Pd}\left(\eta^{2}-\mathrm{BQ}\right)$ such that reliable integration of $(\mathrm{bc}) \mathrm{Pd}\left(\eta^{2}-\right.$ $\left.{ }^{t} \mathrm{BuBQ}\right)$ could not be obtained. For (bc)Pd(tBuBQ) and (bc)Pd(MeBQ) the tert-butyl and methyl peaks were integrated to determine concentrations when the resolution was sufficiently good. Otherwise, the protons of the bound quinone were integrated. For $(b c) \operatorname{Pd}\left(\left(\eta^{2}-B Q\right)\right.$ and $(b c) \operatorname{Pd}\left(\left(\eta^{2}-C l B Q\right)\right.$ the ring protons were integrated to determine concentration. The polynomial baseline correction feature of MestReNova 12.0.1 was used for baseline correction. In the exchange reaction of ${ }^{t} \mathrm{BuBQ}$ with (bc) $\mathrm{Pd}(\mathrm{MeBQ})$, the formation of a small unidentified peak with a temperature dependent chemical shift is observed between $\sim 5.6$ and 6.3 ppm (denoted with asterisk $\left(^{*}\right)$ in top spectral stack in Fig. S1). The identity of the unknown peak was not the subject of thorough investigation. However, since the chemical shift of the peak is temperature dependent, while the peaks of the Pd-quinone complexes are not, we conclude that it is not associated with the Pd-quinone complexes. We speculate that it results from an exchangeable proton (e.g. from acetic acid) present in the reaction mixture or impurity in the ${ }^{t} \mathrm{BuBQ}$ starting material.
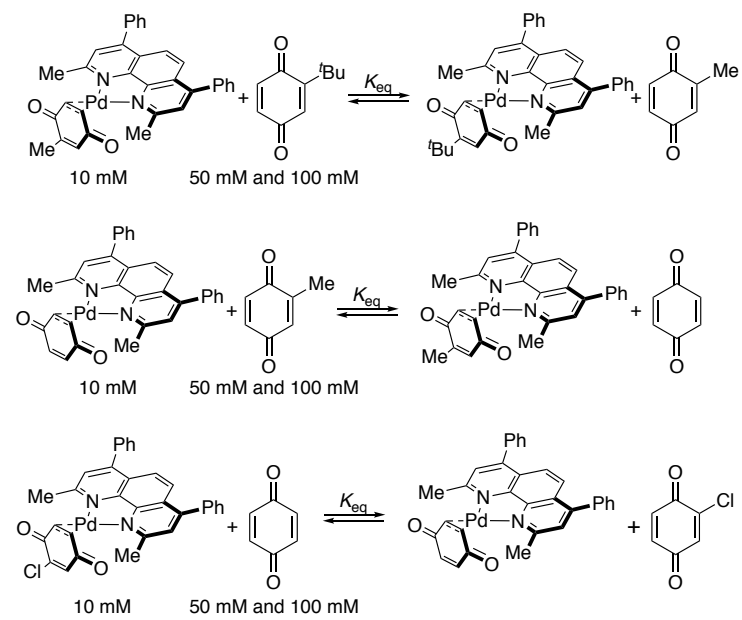

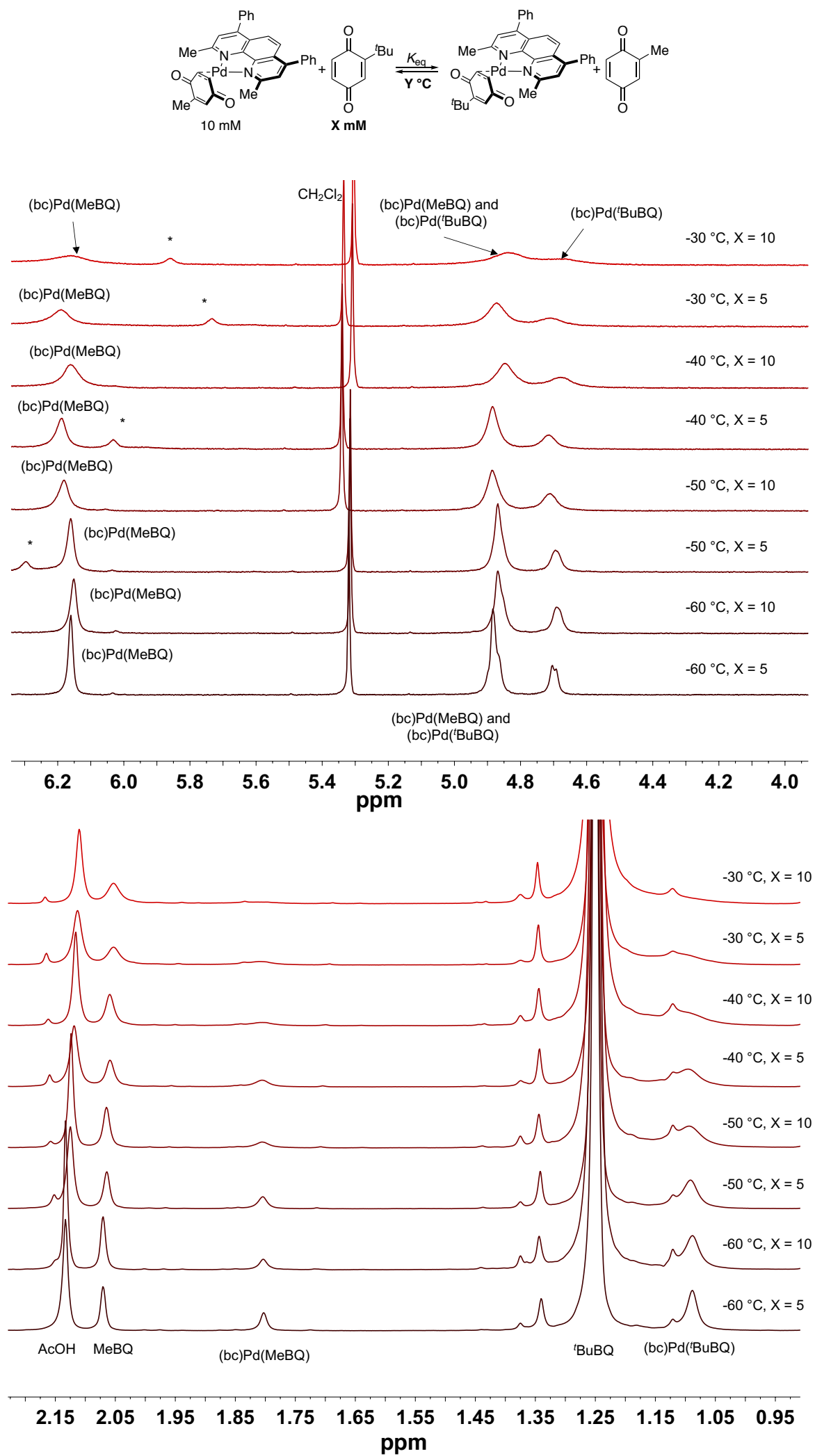

Figure S1. Variable temperature ${ }^{1} \mathrm{H}$ NMR Spectra for exchange of ${ }^{t} \mathrm{BuBQ}$ with (bc)Pd(MeBQ). Asterisk $\left(^{*}\right)$ denotes unidentified, temperature-dependent peak. See above text for details. 
Table S3. Equilibria data and van't Hoff plot for exchange of ${ }^{t} \mathrm{BuBQ}$ with (bc) $\mathrm{Pd}(\mathrm{MeBQ})$.

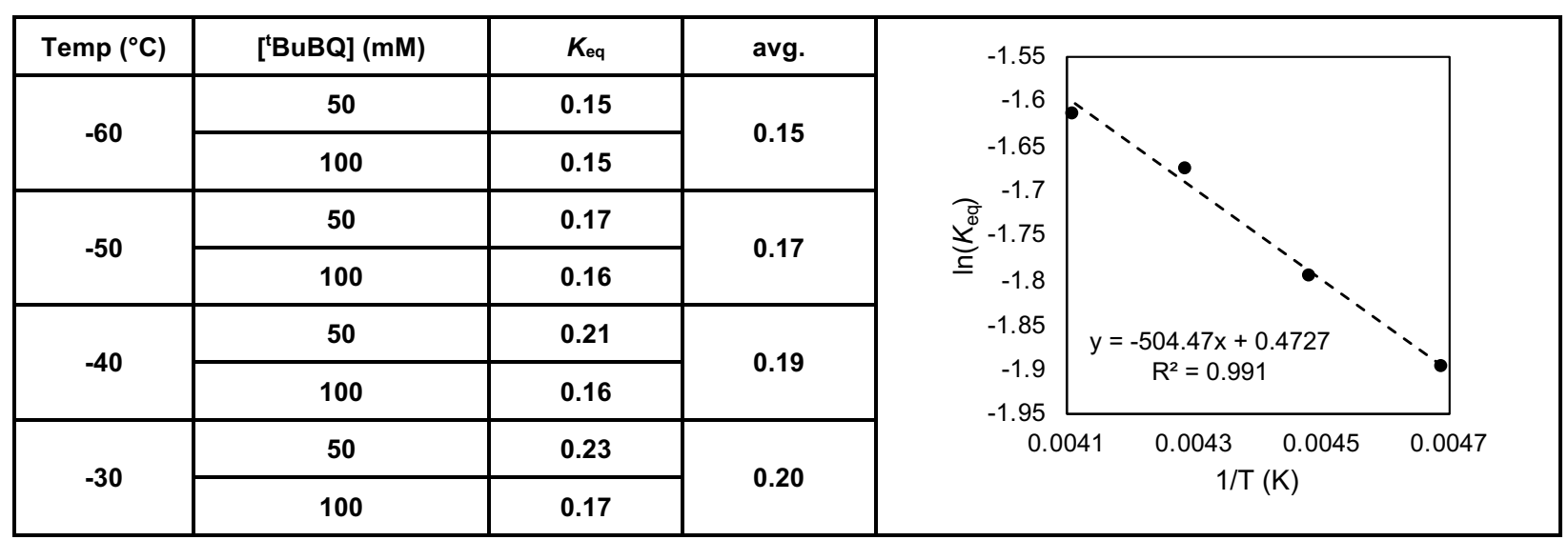



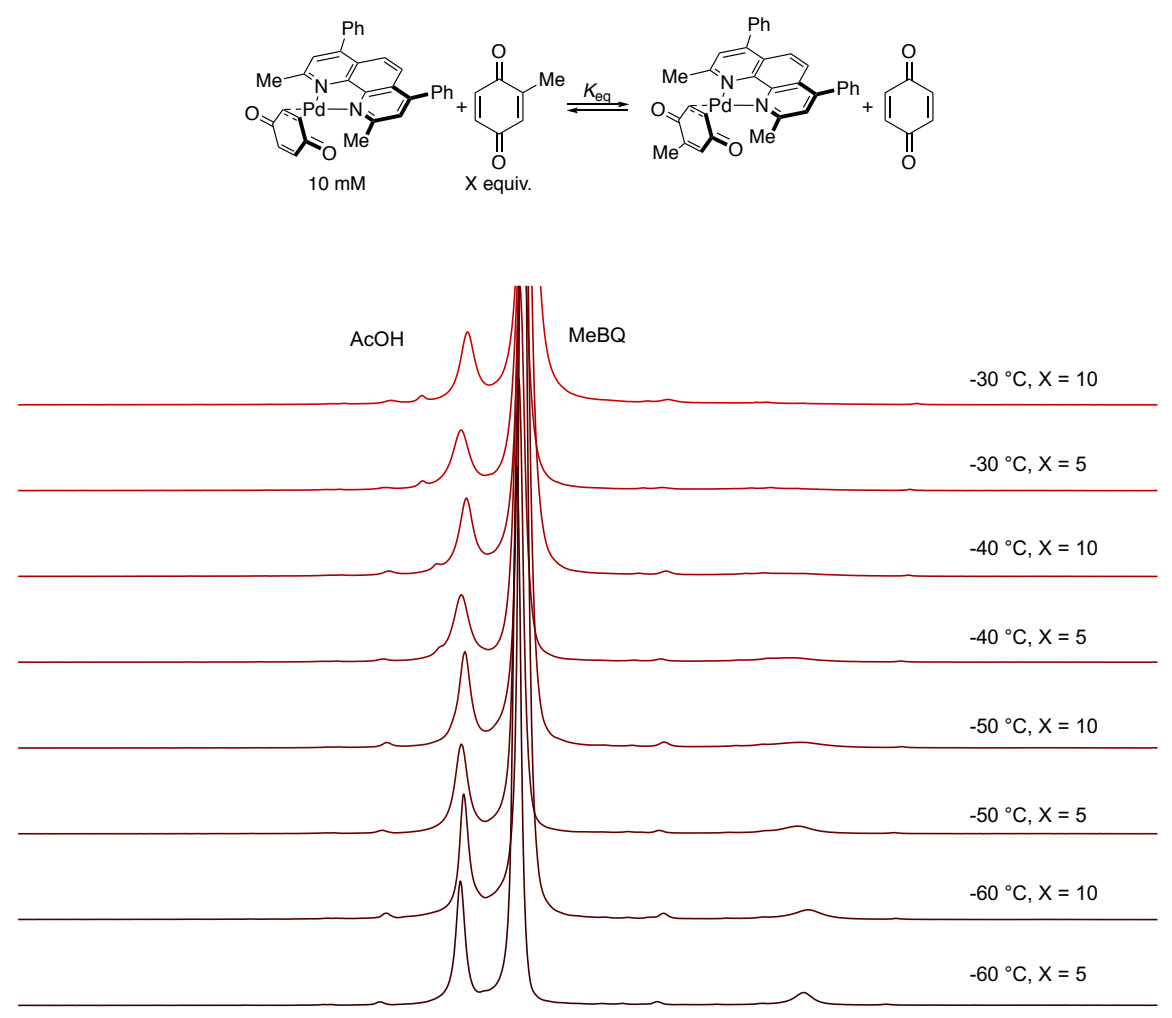

(bc) $P d(M e B Q)$
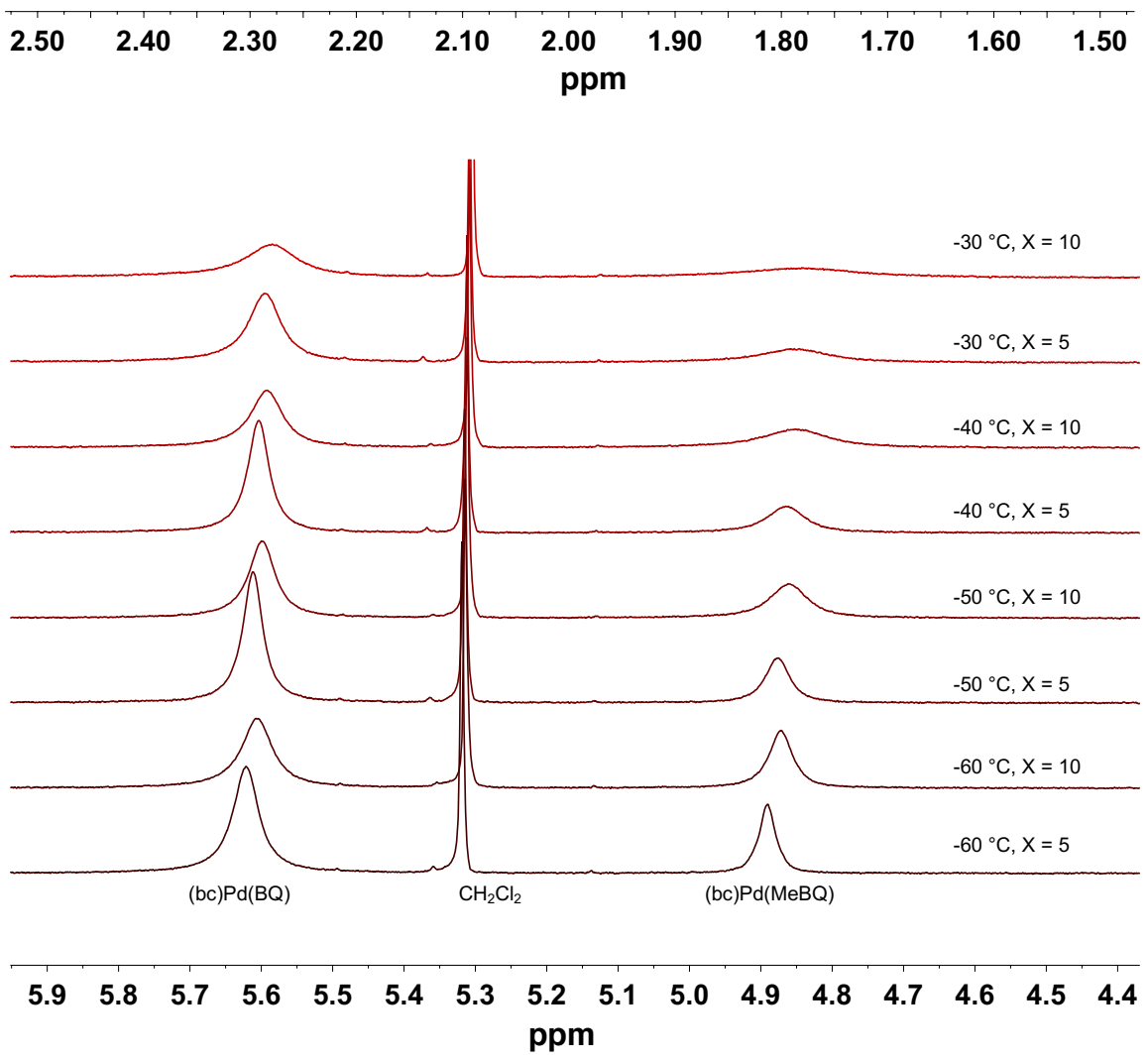

Figure S2. Variable temperature ${ }^{1} \mathrm{H}$ NMR Spectra for exchange of MeBQ with (bc)Pd(BQ). 
Table S4. Equilibria data and van't Hoff plot for exchange of MeBQ with (bc)Pd(BQ).

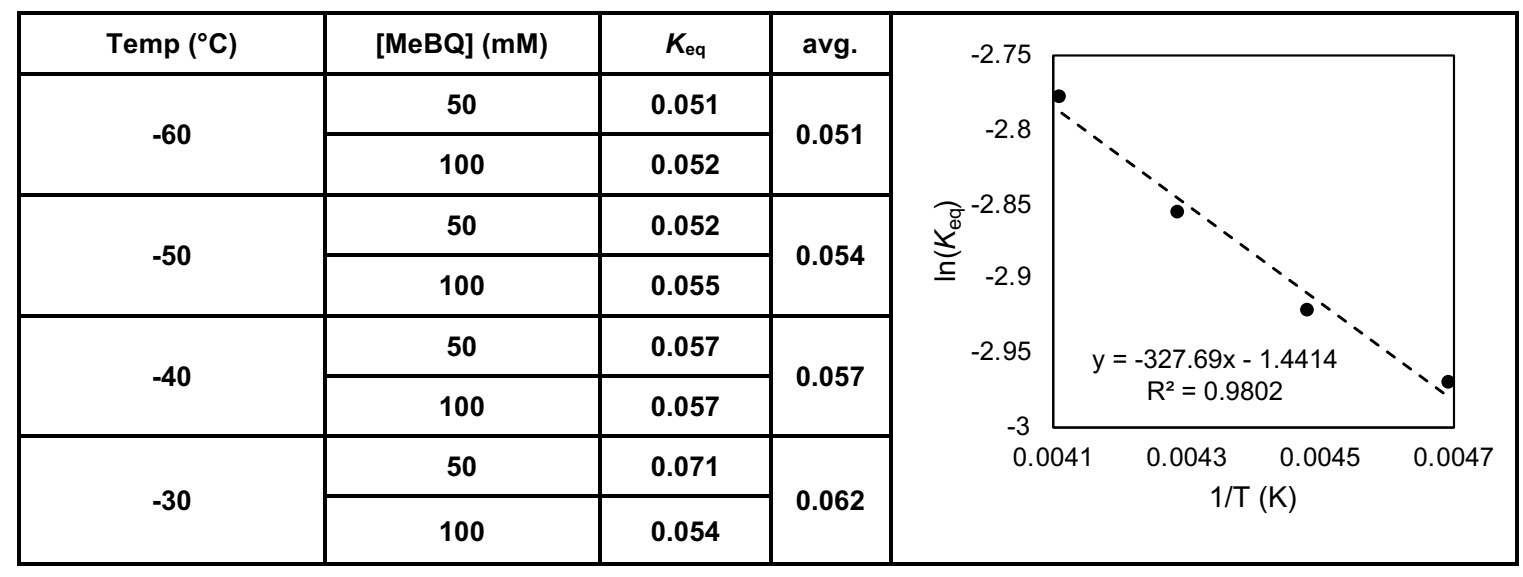




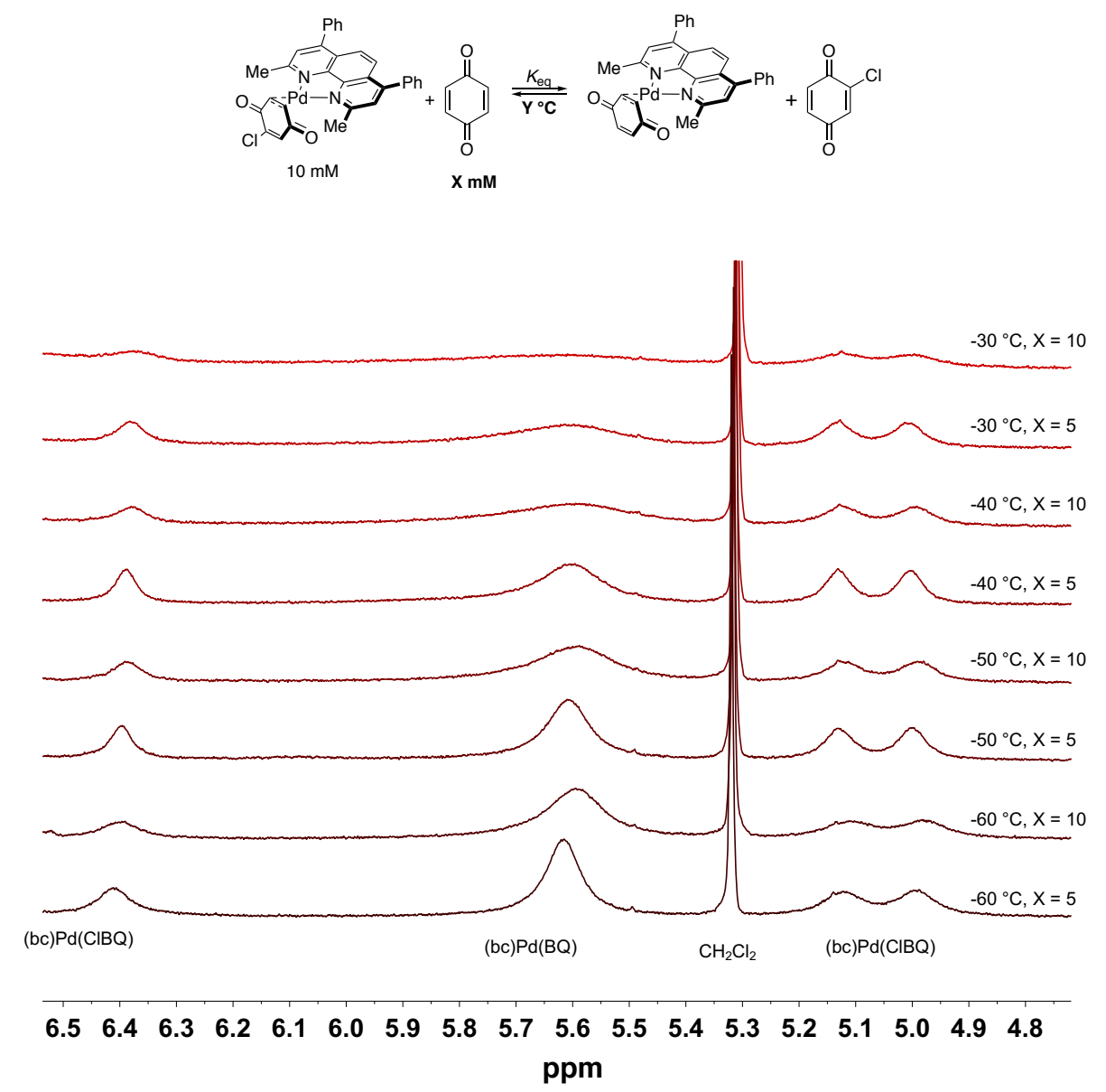

Figure S3. Variable temperature ${ }^{1} \mathrm{H}$ NMR Spectra for exchange of BQ with (bc) $\mathrm{Pd}(\mathrm{ClBQ})$.

Table S5. Equilibria data and van't Hoff plot for exchange of BQ with (bc)Pd(ClBQ).

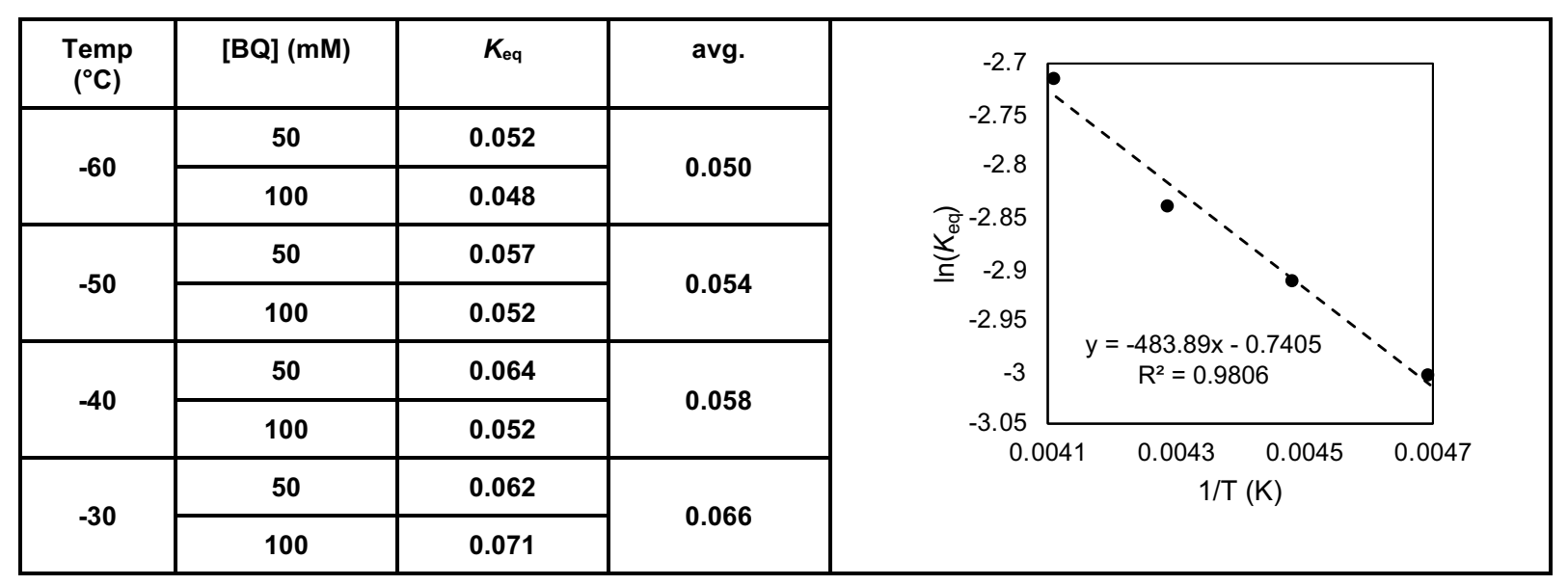




\section{Quinone/hydroquinone Reduction Potential Determination by Open Circuit Potential (OCP) Measurements}

General considerations: Open circuit potentials measurements and cyclic voltammetry measurements were performed at room temperature using a Pine Potentiostat/Galvanostat. The experiments were carried out in a three-electrode cell configuration with a glassy carbon working electrode ( $3 \mathrm{~mm}$ diameter) and a platinum wire counter electrode. The potentials were measured versus an $\mathrm{Ag} / \mathrm{AgCl}$ reference electrode (all electrodes from BASi).

Measurements in 1,4-dioxane/AcOH: A $500 \mathrm{mM}$ solution of tetrabutylammonium tetrafluoroborate (TBAB) in a 3:1 mixture of 1,4-dioxane:AcOH (vol:vol) was prepared. Equimolar quantities of BQ and $\mathrm{H}_{2} \mathrm{Q}(0.1 \mathrm{mmol})$ were weighed into separate vials. The $\mathrm{BQ}$ and $\mathrm{H}_{2} \mathrm{Q}$ were dissolved in $10 \mathrm{~mL}$ of the TBAB solution and the solution was purged with nitrogen for several minutes. An initial CV was recorded before the OCP was measured for 30-40 min. Following the OCP measurement, a second CV was recorded. Ferrocene was added to the $\mathrm{BQ} / \mathrm{H}_{2} \mathrm{Q}$ solution and a $\mathrm{CV}$ was recorded for reference. The value for the OCP was obtained from the average of the data following an initial equilibration period (approximately $200 \mathrm{~s}$ ).

Open Circuit Potential vs. Time

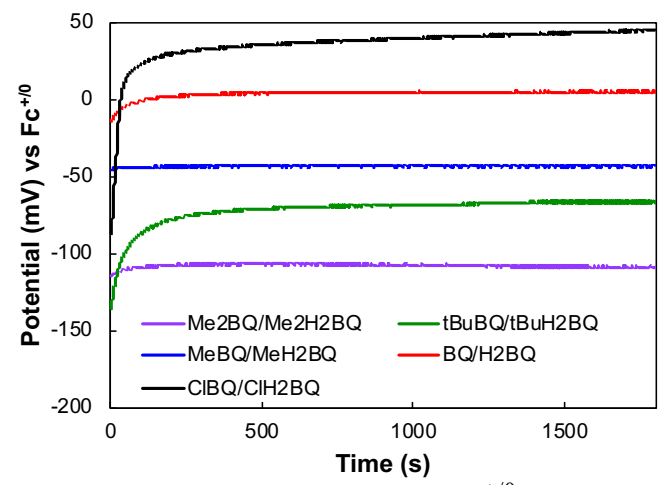

Figure S4. Open circuit potential measurements (vs. $\mathrm{Fc}^{+/ 0}$ ) for $1: 1$ mixtures of $\mathrm{Q} / \mathrm{H}_{2} \mathrm{Q}$ in $3: 1$ 1,4dioxane:AcOH with tetrabutylammonium tetrafluoroborate supporting electrolyte $(500 \mathrm{mM})$.

Measurements in chloroform/AcOH: A $500 \mathrm{mM}$ solution of tetrabutylammonium hexafluorophosphate (TBAP) in a $1.5 \mathrm{M}$ solution of $\mathrm{AcOH}$ in chloroform was prepared. Equimolar quantities of $\mathrm{BQ}$ and $\mathrm{H}_{2} \mathrm{Q}$ $(0.1 \mathrm{mmol})$ were weighed into separate vials. The $\mathrm{BQ}$ and $\mathrm{H}_{2} \mathrm{Q}$ were dissolved in $10 \mathrm{~mL}$ of the TBAP solution and the solution was purged with nitrogen for several minutes. An initial CV was recorded before the OCP was measured for 30-40 min. Following the OCP measurement, a second CV was recorded. Ferrocene was added to the $\mathrm{BQ} / \mathrm{H}_{2} \mathrm{BQ}$ solution and a $\mathrm{CV}$ was recorded for reference. In the case of 2chlorobenzoquinone, $\mathrm{ClBQ} / \mathrm{ClH}_{2} \mathrm{BQ}$ redox events obscured the peaks of the ferrocene couple, so the ferrocene reference was recorded in fresh solvent free of quinone immediately following the measurement of the OCP. The value for the OCP was obtained from the average of the data following an initial equilibration period (approximately $200 \mathrm{~s}$ ). 


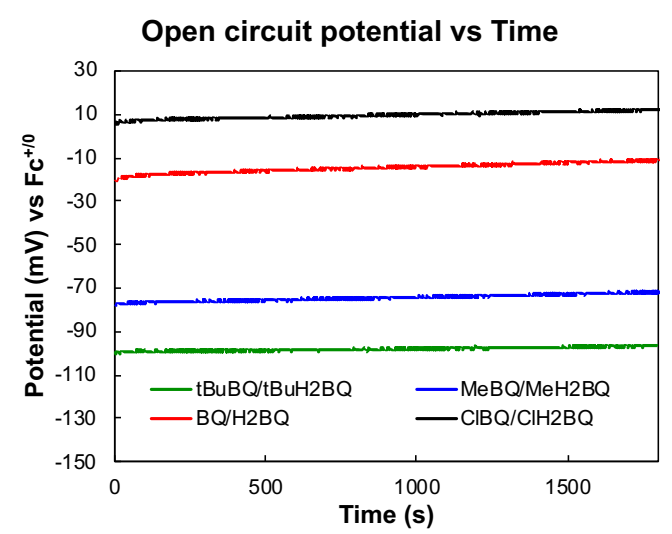

Figure S5. Open circuit potential measurements $\left(\mathrm{vs} \mathrm{Fc}^{+/ 0}\right.$ ) for $1: 1$ mixtures of $\mathrm{Q} / \mathrm{H}_{2} \mathrm{Q}$ derivatives in chloroform/AcOH $(1.5 \mathrm{M} \mathrm{AcOH})$ with tetrabutylammonium hexafluorophosphate supporting electrolyte $(500 \mathrm{mM})$.

\section{Synthesis of (bathocuproine)Pd complexes}

\section{Synthesis of (bathocuproine) $\operatorname{Pd}(\mathrm{OAc})_{2}$}

Palladium acetate $(1.56 \mathrm{~g}, 6.94 \mathrm{mmol})$ and bathocuproine $(2.5 \mathrm{~g}, 6.94 \mathrm{mmol})$ were dissolved in $25 \mathrm{~mL}$ of dichloromethane and stirred at room temperature overnight under air. The solvent was removed in vacuo to yield (bc) $\mathrm{Pd}(\mathrm{OAc})_{2}(4.0 \mathrm{~g}, 98 \%$ yield $)$.

${ }^{1} \mathrm{H}$ NMR (500 MHz, Chloroform-d) $\delta 7.79(\mathrm{~s}, 2 \mathrm{H}), 7.559-7.52(\mathrm{~m}, 6 \mathrm{H}), 7.49-7.44(\mathrm{~m}, 4 \mathrm{H}), 7.42(\mathrm{~s}, 2 \mathrm{H})$, $2.99(\mathrm{~s}, 6 \mathrm{H}), 2.03(\mathrm{~s}, 6 \mathrm{H})$

${ }^{13} \mathrm{C}$ NMR $\left(126 \mathrm{MHz}, \mathrm{CDCl}_{3}\right) \delta 178.57,164.87,150.99,148.38,135.55,129.87,129.40,129.21,126.99$, $126.65,124.39,24.88,23.09$.

\section{Synthesis of (bc)Pd( $\left.{ }^{t} \mathrm{BuBQ}\right)$}

Into an over-dried $100 \mathrm{~mL}$ Teflon stoppered bomb flask equipped with a stir bar was added ${ }^{t} \mathrm{BuH}_{2} \mathrm{BQ}(71.0$ $\mathrm{mg}, 0.427 \mathrm{mmol})$ and $(\mathrm{bc}) \mathrm{Pd}(\mathrm{OAc})_{2}(250 \mathrm{mg}, 0.427 \mathrm{mmol})$. The flask was evacuated, filled with $50 \mathrm{~mL}$ chloroform, and stirred at room temperature overnight. Chloroform was removed in vacuo, $10 \mathrm{~mL}$ of toluene were added and the red-orange solid was stirred for about $10 \mathrm{~min}$ before the toluene was removed in vacuo to remove acetic acid that is a byproduct of the reaction. This process was repeated three times. The flask was transferred to a glovebox, where the solid was dissolved in chloroform $(\sim 10 \mathrm{~mL})$ and filtered through a pad of Celite filter powder. The chloroform was removed under reduced pressure, and the resulting red-orange solid was washed with pentane $(\sim 20 \mathrm{~mL})$ and toluene $(\sim 5 \mathrm{~mL})$ to yield $(\mathrm{bc}) \mathrm{Pd}\left({ }^{t} \mathrm{BuBQ}\right)$ ( $223.5 \mathrm{mg}, 83 \%$ yield). Single crystals suitable for X-ray diffraction were grown from vapor diffusion of pentane into a saturated toluene solution of $\mathrm{Pd}($ bathocuproine $)\left({ }^{t} \mathrm{BuBQ}\right)$.

${ }^{1} \mathrm{H}$ NMR $(500 \mathrm{MHz}$, Chloroform- $d$ ) $\delta 7.81(\mathrm{~s}, 2 \mathrm{H}), 7.63(\mathrm{~d}, J=3.1 \mathrm{~Hz}, 2 \mathrm{H}), 7.58-7.52(\mathrm{~m}, 6 \mathrm{H}), 7.52-7.45$ $(\mathrm{m}, 3 \mathrm{H}), 6.15(\mathrm{~d}, J=2.2 \mathrm{~Hz}, 1 \mathrm{H}), 4.78(\mathrm{dd}, J=7.0,2.2 \mathrm{~Hz}, 1 \mathrm{H}), 4.64(\mathrm{~d}, J=6.9 \mathrm{~Hz}, 1 \mathrm{H}), 3.08(\mathrm{~s}, 3 \mathrm{H}), 3.02$ $(\mathrm{s}, 3 \mathrm{H}), 1.14(\mathrm{~s}, 9 \mathrm{fH})$.

${ }^{13} \mathrm{C}\left\{{ }^{1} \mathrm{H}\right\}$ NMR $\left(126 \mathrm{MHz}, \mathrm{CDCl}_{3}\right) \delta 191.39,190.71,162.61,157.14,150.02,146.72,146.69,136.88$, $136.84,134.13,129.59,129.55,129.33,129.31,129.01,126.20,126.01,125.91,125.81,123.65,123.60$, $57.49,55.91,35.21,29.40,28.57,28.41$.

FTIR (ATR, $\left.\mathrm{cm}^{-1}\right): 1583(\mathrm{C}=\mathrm{O}), 1610(\mathrm{C}=\mathrm{O})$

\section{Synthesis of (bc)Pd(MeBQ)}

(bc) $\mathrm{Pd}(\mathrm{OAc})_{2}(100 \mathrm{mg}, 0.171 \mathrm{mmol})$ and $\mathrm{MeH}_{2} \mathrm{BQ}(21.22 \mathrm{mg}, 0.171 \mathrm{mmol})$ were dissolved in $20 \mathrm{~mL}$ of chloroform in a $100 \mathrm{~mL}$ Teflon stoppered bomb flask and stirred at room temperature overnight. Pentane was vacuum transferred to the reaction to precipitate the product before it was moved to a glovebox. The 
resulting brown solid was washed with pentane, toluene and THF to yield the yield $32 \mathrm{mg}$ of $(\mathrm{bc}) \mathrm{Pd}(\mathrm{MeBQ})$ (32\% yield).

${ }^{1} \mathrm{H}$ NMR (400 MHz, Chloroform- $d$ ) $\delta 7.80(\mathrm{~s}, 2 \mathrm{H}), 7.62(\mathrm{~s}, 2 \mathrm{H}), 7.59-7.42(\mathrm{~m}, 10 \mathrm{H}), 6.15(\mathrm{~s}, 1 \mathrm{H}), 4.78$ (s, 2H), 3.07 (s, 3H), $3.05(\mathrm{~s}, 3 \mathrm{H}), 1.84(\mathrm{~s}, 3 \mathrm{H})$.

${ }^{13} \mathrm{C}\left\{{ }^{1} \mathrm{H}\right\}$ NMR $\left(126 \mathrm{MHz}, \mathrm{CDCl}_{3}\right) \delta 191.49,191.02,166.45,162.65,151.07,150.09,148.89,146.72$, $146.60,136.83,135.69,135.48,130.01,129.54,129.32$, 126.92, 126.11, 126.00, 124.29, 123.62, 55.87, $28.39,28.08,16.95$

FTIR (ATR, $\left.\mathrm{cm}^{-1}\right): 1603(\mathrm{C}=\mathrm{O}), 1613(\mathrm{C}=\mathrm{O})$

\section{Synthesis of (bc)Pd(BQ)}

(bc) $\cdot \mathrm{Pd}(\mathrm{OAc})_{2}(100 \mathrm{mg}, 0.171 \mathrm{mmol})$ and $\mathrm{H}_{2} \mathrm{BQ}(18.9 \mathrm{mg}, 0.171 \mathrm{mmol})$ were dissolved in $\sim 30 \mathrm{~mL}$ of chloroform in a $100 \mathrm{~mL}$ Teflon stoppered bomb flask and stirred at room temperature overnight. Pentane was vacuum transferred to the reaction to precipitate the product before it was moved to a glovebox. The resulting brown solid was washed with pentane to yield $34.1 \mathrm{mg}$ of (bc)Pd(BQ) (35\% yield). The product decomposed upon removal of solvent, so rigorous drying was forgone, hence the substantial pentane peak in the NMR spectra.

${ }^{1} \mathrm{H}$ NMR (400 MHz, Chloroform- $d$ ) $\delta 7.81(\mathrm{~s}, 2 \mathrm{H}), 7.63(\mathrm{~s}, 2 \mathrm{H}), 7.59-7.46(\mathrm{~m}, 10 \mathrm{H}), 5.55(\mathrm{~s}, 4 \mathrm{H}), 3.06$ $(\mathrm{s}, 6 \mathrm{H})$.

${ }^{13} \mathrm{C}\left\{{ }^{1} \mathrm{H}\right\}$ NMR $\left(126 \mathrm{MHz}, \mathrm{CDCl}_{3}\right) \delta 190.41,162.47,150.06,146.58,136.63,129.39,129.21,128.90$, $126.01,123.52,116.14,28.06$.

FTIR $\left(\mathrm{ATR}, \mathrm{cm}^{-1}\right): 1642(\mathrm{C}=\mathrm{O})$

\section{Synthesis of (bc)Pd(CIBQ)}

Bathocuproine $\cdot \mathrm{Pd}(\mathrm{OAc})_{2}(100 \mathrm{mg}, 0.171 \mathrm{mmol})$ and $\mathrm{ClH}_{2} \mathrm{BQ}(24.7 \mathrm{mg}, 0.171 \mathrm{mmol})$ were dissolved in $\sim 20 \mathrm{~mL}$ of chloroform and stirred at room temperature overnight. The product was precipitated out of solution with pentane and the resulting brown solid was washed with pentane, toluene, and THF to yield (bc) $\mathrm{Pd}(\mathrm{ClBQ})$ in $69 \%$ yield $(71.9 \mathrm{mg})$ as a brown solid.

${ }^{1} \mathrm{H}$ NMR (400 MHz, Chloroform- $d$ ) $\delta 7.82(\mathrm{~s}, 2 \mathrm{H}), 7.63(\mathrm{~s}, 2 \mathrm{H}), 7.60-7.45(\mathrm{~m}, 10 \mathrm{H}), 6.33(\mathrm{~s}, 1 \mathrm{H}), 5.13$ $(\mathrm{d}, J=7.3 \mathrm{~Hz}, 1 \mathrm{H}), 5.01(\mathrm{~d}, J=7.4 \mathrm{~Hz}, 1 \mathrm{H}), 3.04(\mathrm{~s}, 3 \mathrm{H}), 3.02(\mathrm{~s}, 3 \mathrm{H})$.

${ }^{13} \mathrm{C}\left\{{ }^{1} \mathrm{H}\right\}$ NMR $\left(126 \mathrm{MHz}, \mathrm{CDCl}_{3}\right) \delta 188.76,182.88,162.76,162.66,150.38,136.71,129.53,129.40$, 129.06, 126.14, 125.14, 67.09, 66.82, 28.24, 28.09.

FTIR (ATR, $\left.\mathrm{cm}^{-1}\right): 1620(\mathrm{C}=\mathrm{O}), 1642(\mathrm{C}=\mathrm{O})$ 
8. NMR Spectroscopic data

${ }^{1}$ H NMR: (bc)Pd(OAc) 2

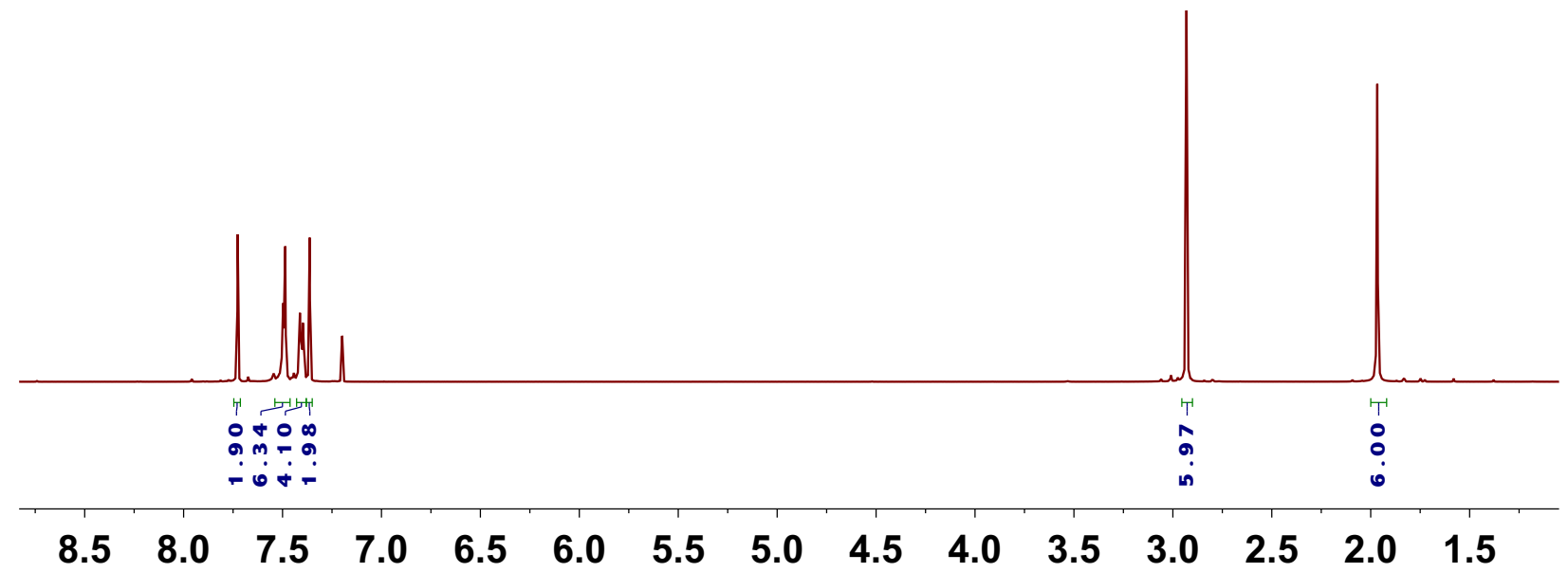

${ }^{13} \mathrm{C}\left\{{ }^{1} \mathrm{H}\right\}$ NMR: (bc)Pd(OAc) ${ }_{2}$

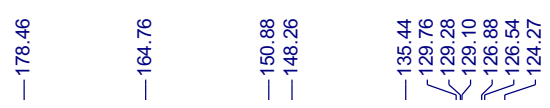

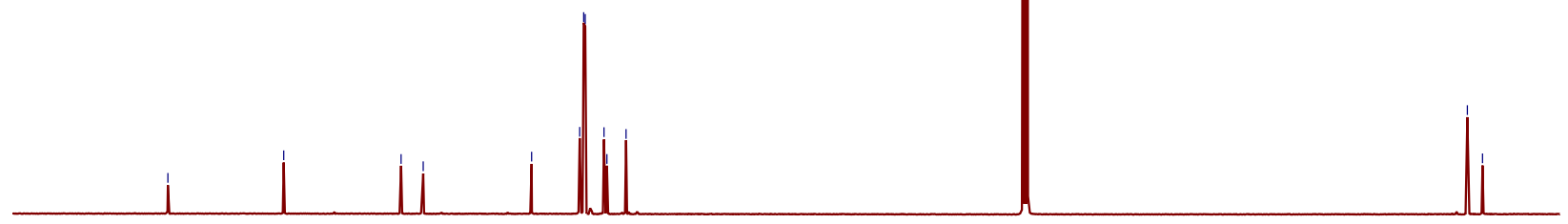

$\begin{array}{llllllllllllllllll}190 & 180 & 170 & 160 & 150 & 140 & 130 & 120 & 110 & 100 & 90 & 80 & 70 & 60 & 50 & 40 & 30 & 20\end{array}$ 
${ }^{1}$ H NMR: (bc)Pd( ${ }^{t}$ BuBQ)

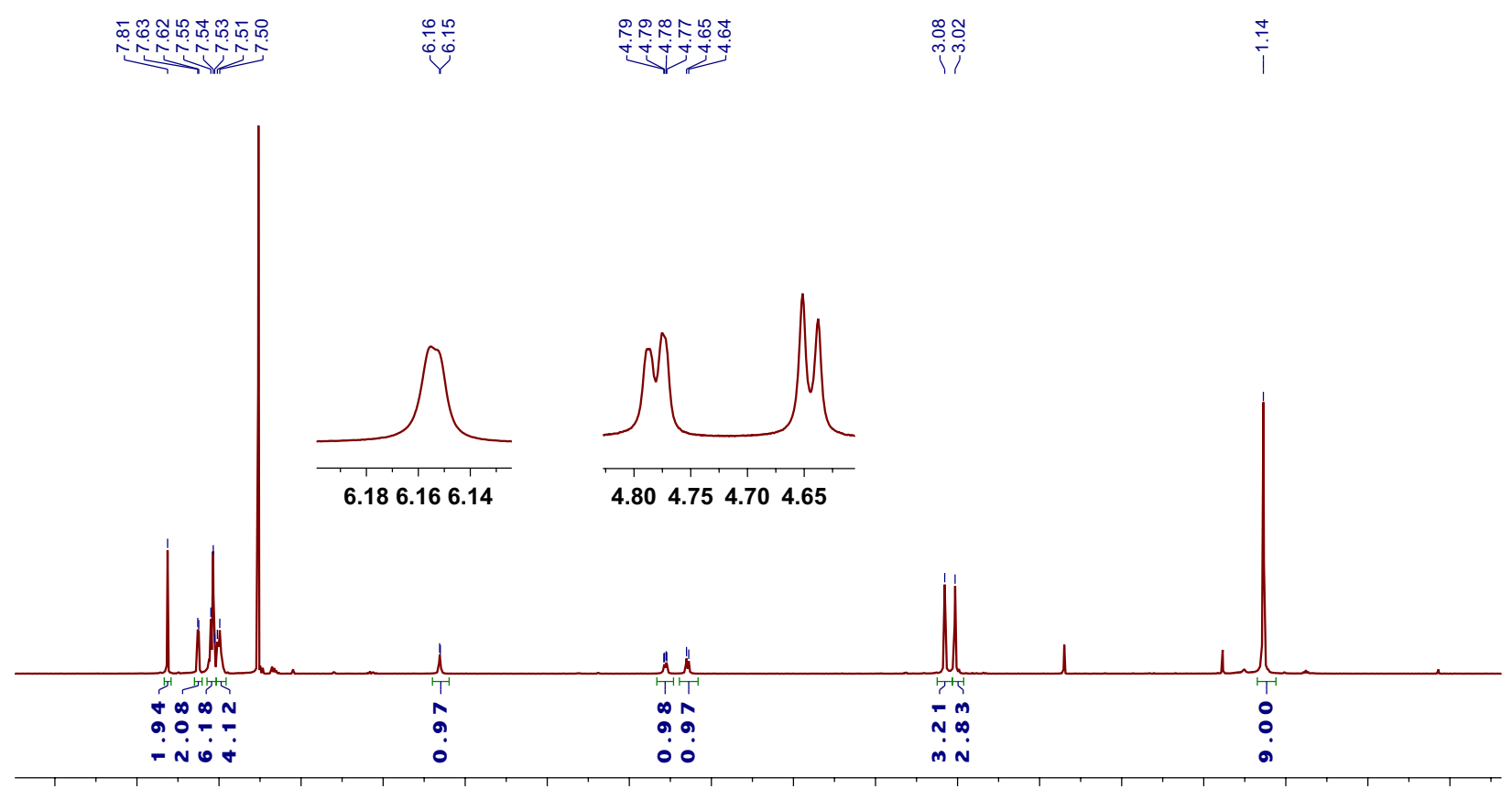

$\begin{array}{llllllllllllllllll}8.5 & 8.0 & 7.5 & 7.0 & 6.5 & 6.0 & 5.5 & 5.0 & 4.5 & 4.0 & 3.5 & 3.0 & 2.5 & 2.0 & 1.5 & 1.0 & 0.5 & 0.0\end{array}$ ${ }^{13} \mathrm{C}\left\{{ }^{1} \mathrm{H}\right\}$ NMR: (bc)Pd( $\left({ }^{t} \mathrm{BuBQ}\right)$

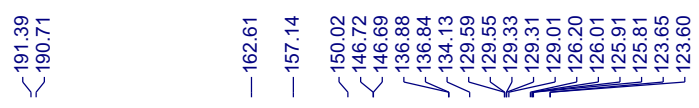

1.

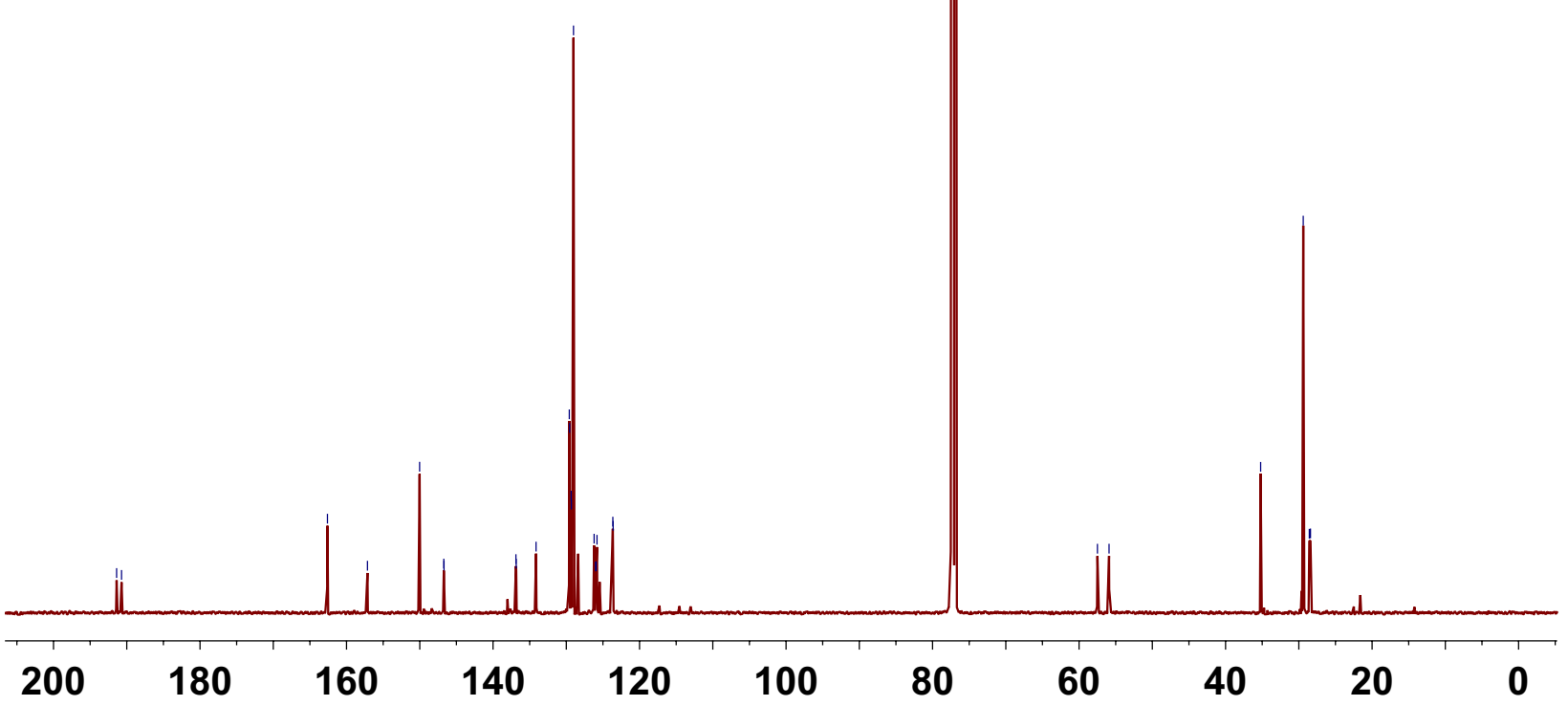


${ }^{1}$ H NMR: (bc)Pd(MeBQ)

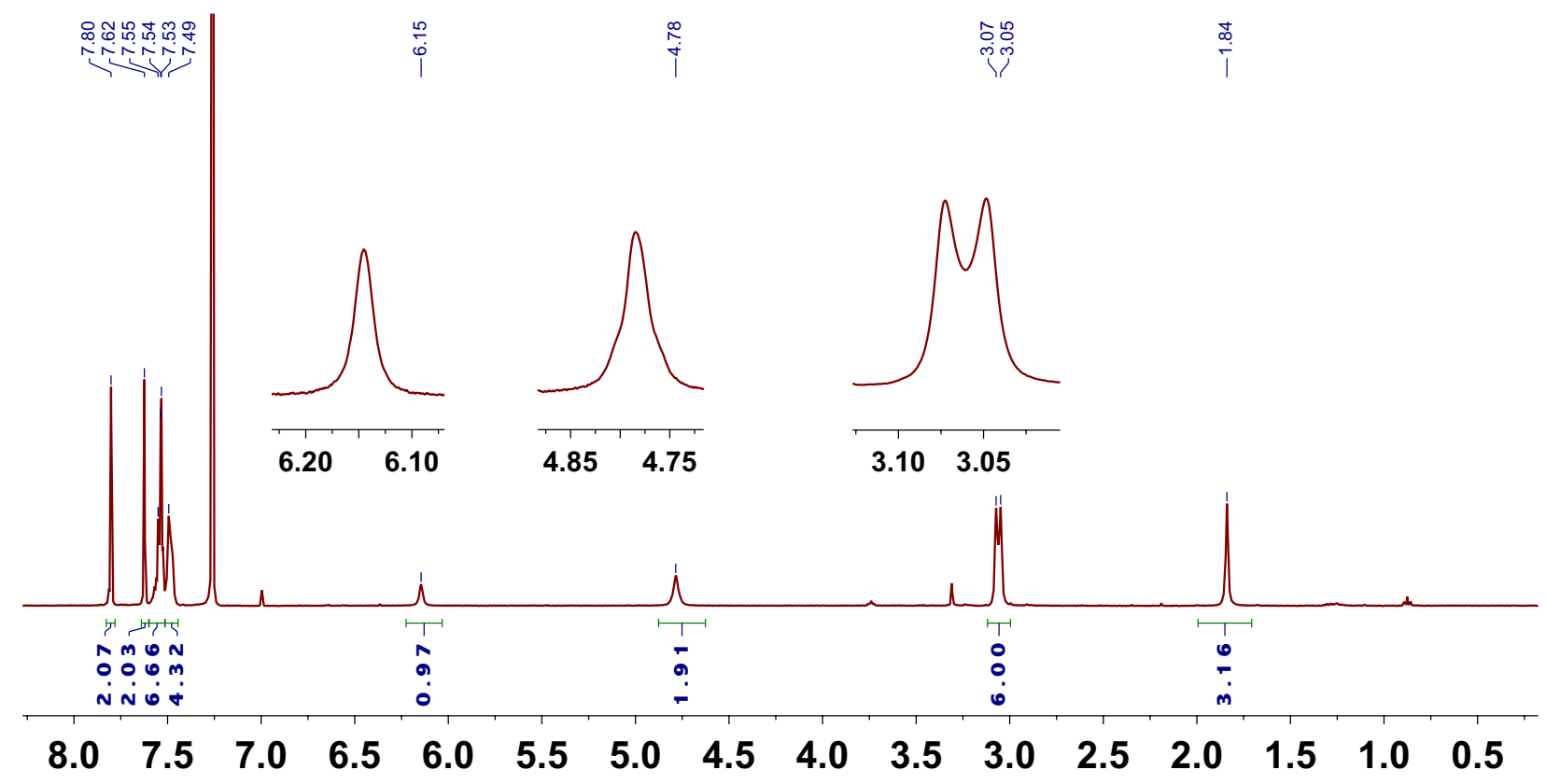

${ }^{13} \mathrm{C}\left\{{ }^{1} \mathrm{H}\right\}$ NMR: (bc)Pd(MeBQ)

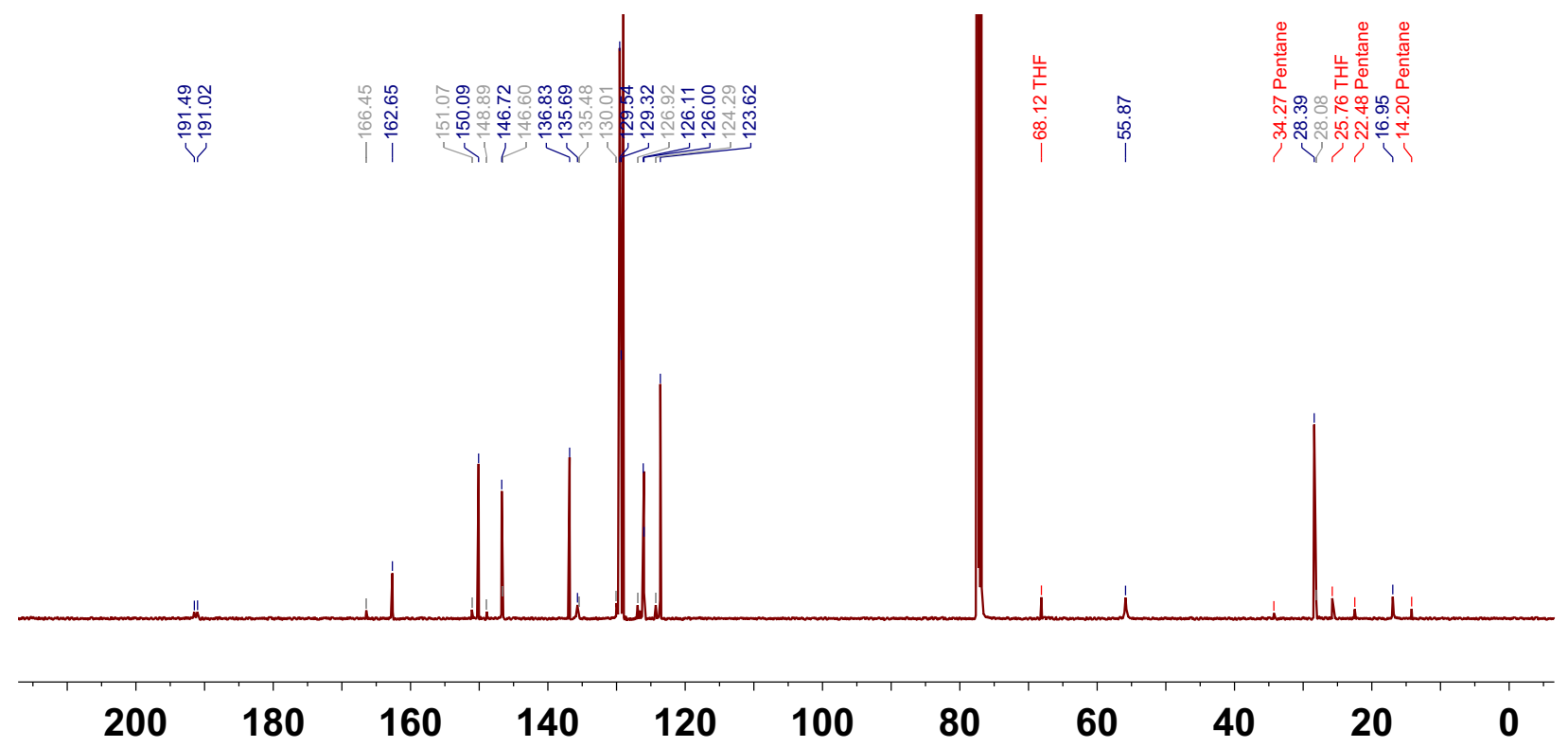


${ }^{1}$ H NMR: (bc)Pd(BQ)

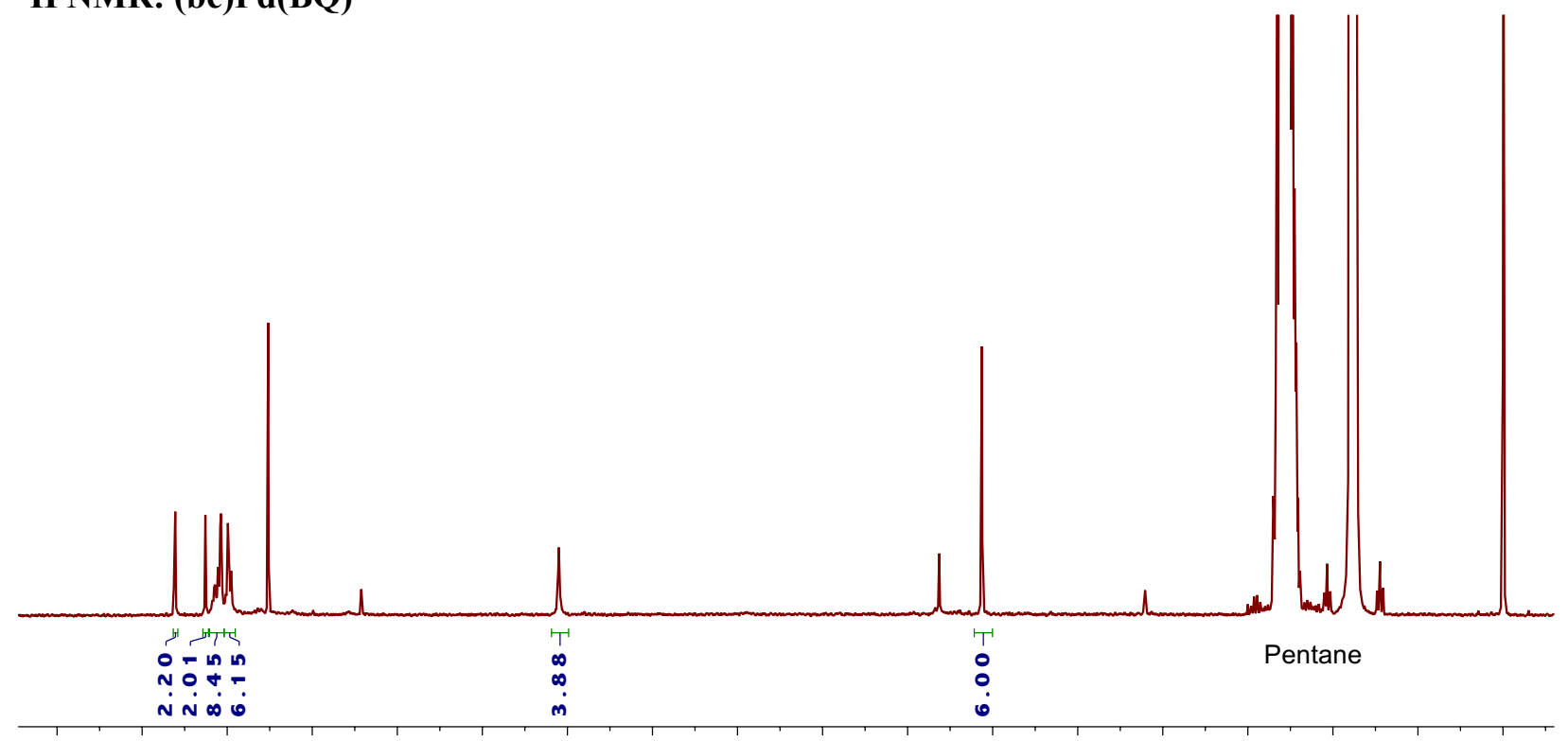

$\begin{array}{llllllllllllllllll}8.5 & 8.0 & 7.5 & 7.0 & 6.5 & 6.0 & 5.5 & 5.0 & 4.5 & 4.0 & 3.5 & 3.0 & 2.5 & 2.0 & 1.5 & 1.0 & 0.5 & 0.0\end{array}$ ${ }^{13} \mathrm{C}\left\{{ }^{1} \mathrm{H}\right\}$ NMR: (bc)Pd(BQ)

\begin{tabular}{|c|c|c|c|}
\hline & $\begin{array}{l}\text { f } \\
\text { ฮิ } \\
\text { I }\end{array}$ & 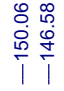 & 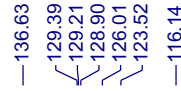 \\
\hline
\end{tabular}

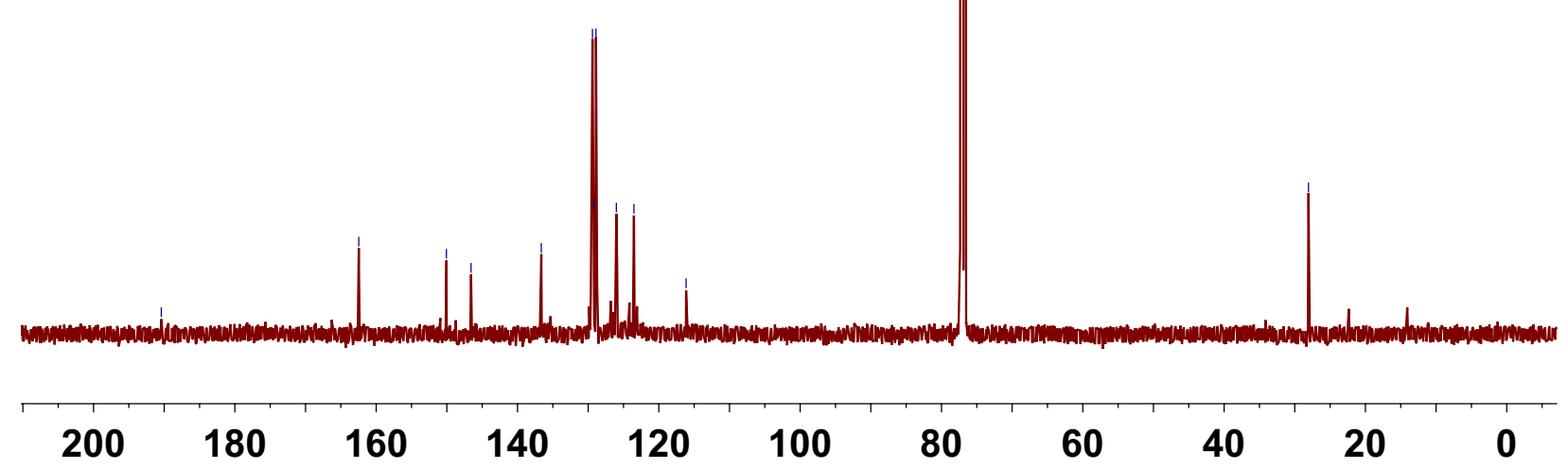


${ }^{1}$ H NMR: (bc)Pd(CIBQ)

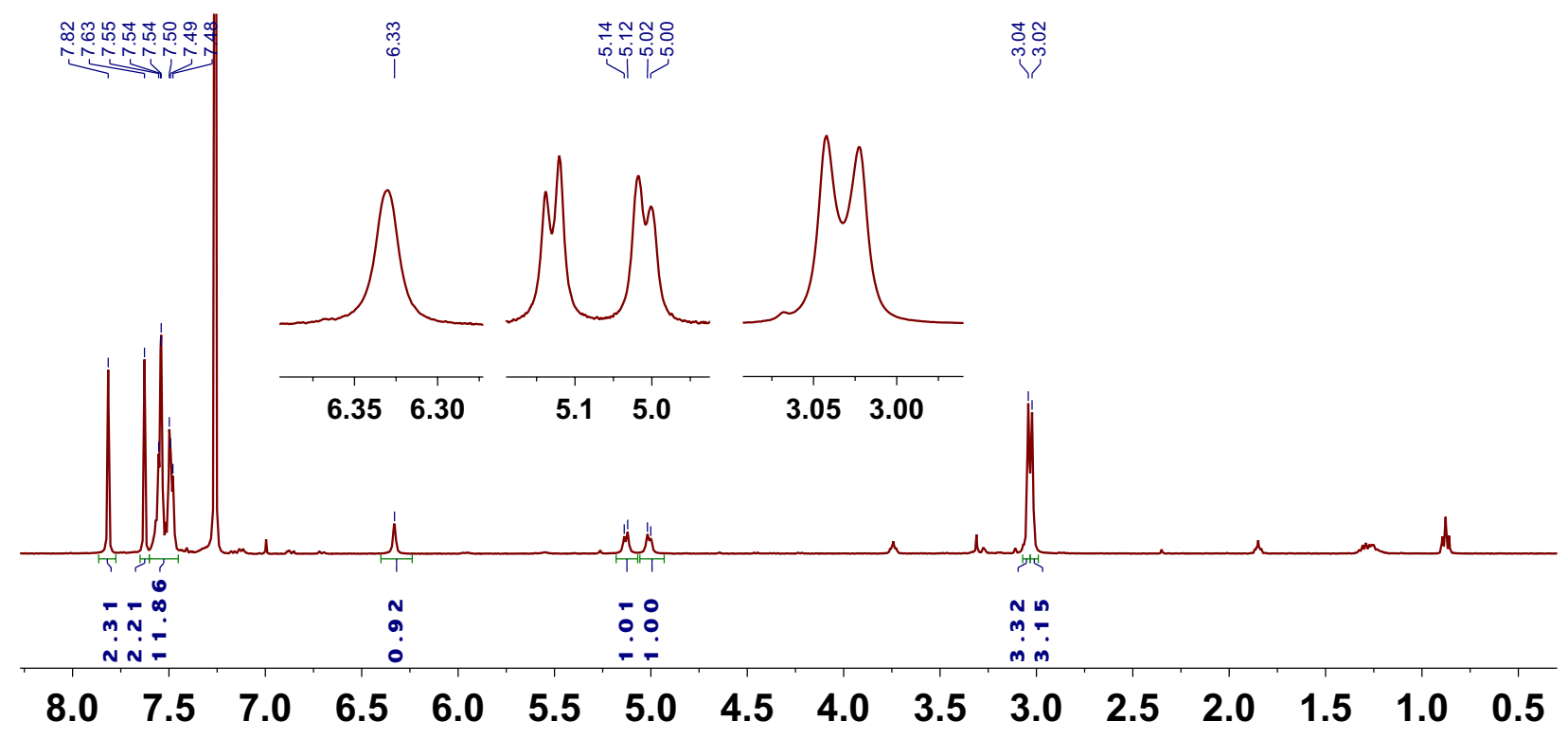

${ }^{13} \mathrm{C}\left\{{ }^{1} \mathrm{H}\right\}$ NMR: (bc)Pd(ClBQ)

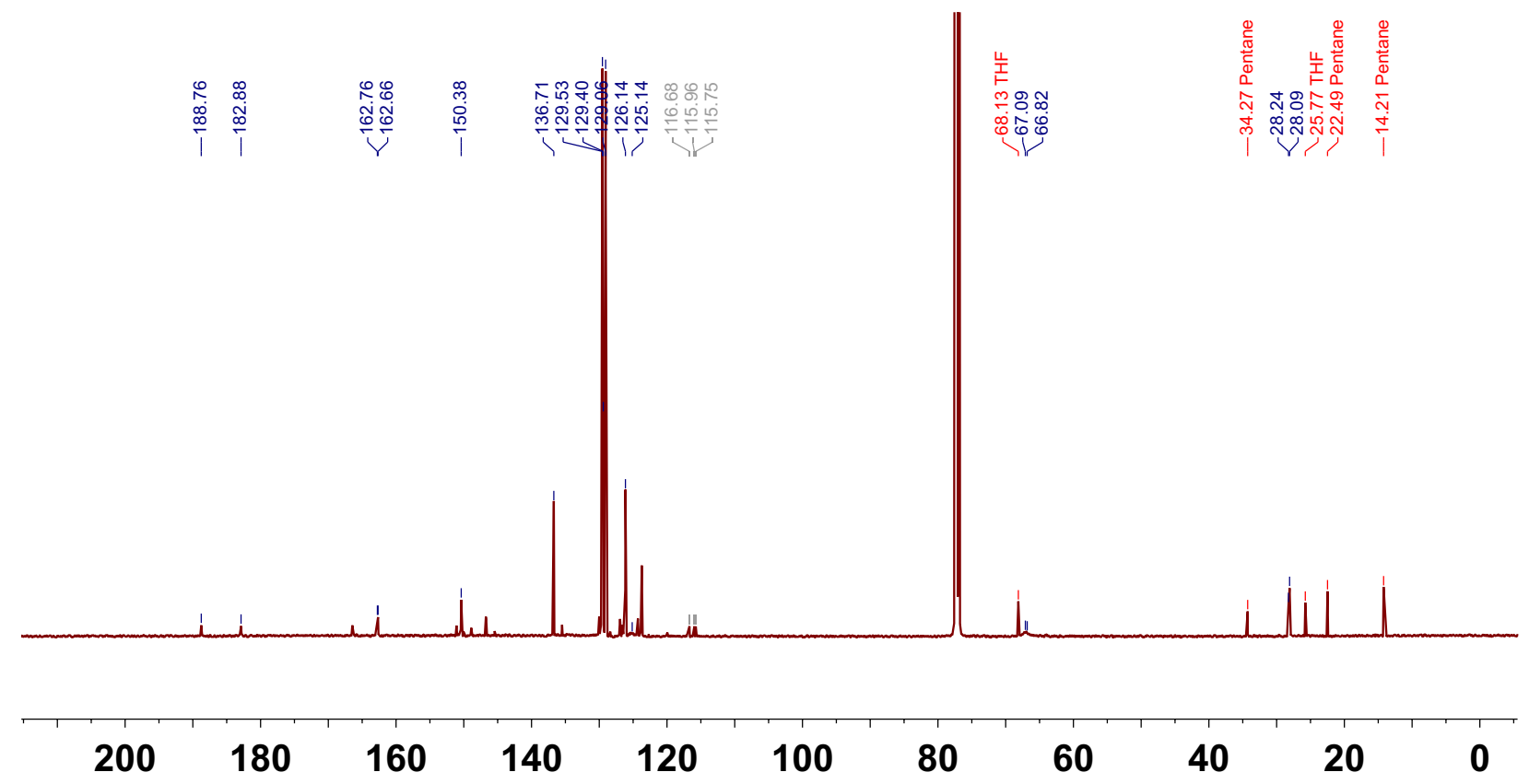




\section{Crystal structure data}

\section{Data Collection}

An orange crystal with approximate dimensions $0.12 \times 0.09 \times 0.01 \mathrm{~mm}^{3}$ was selected under oil under ambient conditions and attached to the tip of a MiTeGen MicroMount $\odot$. The crystal was mounted in a stream of cold nitrogen at 100(1) K and centered in the X-ray beam by using a video camera. The crystal evaluation and data collection were performed on a Bruker Quazar SMART APEXII diffractometer with Mo K $\alpha(\lambda=0.71073 \AA)$ radiation and the diffractometer.

The initial cell constants were obtained from three series of $\omega$ scans at different starting angles. Each series consisted of 12 frames collected at intervals of $0.5^{\circ}$ in a $6^{\circ}$ range about $\omega$ with the exposure time of $20 \mathrm{~s}$ per frame. The reflections were successfully indexed by an automated indexing routine built in the APEXII program suite. The final cell constants were calculated from a set of 9981 strong reflections from the actual data collection. The data were collected by using the full sphere data collection routine to survey the reciprocal space to the extent of a full sphere to a resolution of $0.83 \AA$. A total of 75418 data were harvested by collecting 4 sets of frames with $0.5^{\circ}$ scans in $\omega$ and $\varphi$ with exposure times of 120 sec per frame. These highly redundant datasets were corrected for Lorentz and polarization effects. The absorption correction was based on fitting a function to the empirical transmission surface as sampled by multiple equivalent measurements.

\section{Structure Solution and Refinement}

The systematic absences in the diffraction data were consistent for the space group $P 1$ and $P \overline{1}$ that yielded chemically reasonable and computationally stable results of refinement. ${ }^{3,4}$

A successful solution by charge-flipping provided most non-hydrogen atoms from the E-map. The remaining non-hydrogen atoms were located in an alternating series of least-squares cycles and difference Fourier maps. All non-hydrogen atoms were refined with anisotropic displacement coefficients. All hydrogen atoms were included in the structure factor calculation at idealized positions and were allowed to ride on the neighboring atoms with relative isotropic displacement coefficients.

The asymmetric unit contains one molecule of the palladium complex shown in Figure 2 and 2.5 molecules of toluene. The toluene molecules occupy three positions within the asymmetric unit. Toluene molecule C37-C43 is fully occupied and has two disordered components (major occupancy: 61.5(7)\%). Toluene molecule C44-C50 is fully occupied and has two disordered components (major occupancy: 58.2(8)\%). Toluene molecule C51-C57 resides on an inversion center and is half occupied. All toluene molecules were constrained to have an idealized geometry ${ }^{5}$ and thermal parameter constraints were used on the disordered toluene molecules in order to obtain a chemically reasonable and computationally stable refinement.

The final least-squares refinement of 442 parameters against 10640 data resulted in residuals $\mathrm{R}$ (based on $F 2$ for $I \geq 2 \sigma$ ) and $w R$ (based on F2 for all data) of 0.0510 and 0.1363 , respectively. The final difference Fourier map featured 2 peaks of residual electron density $\left(2.59 \mathrm{e} / \mathrm{A}^{3}\right)$ in vicinity of $\mathrm{Pd}$ in chemically unreasonable positions and were considered noise. 


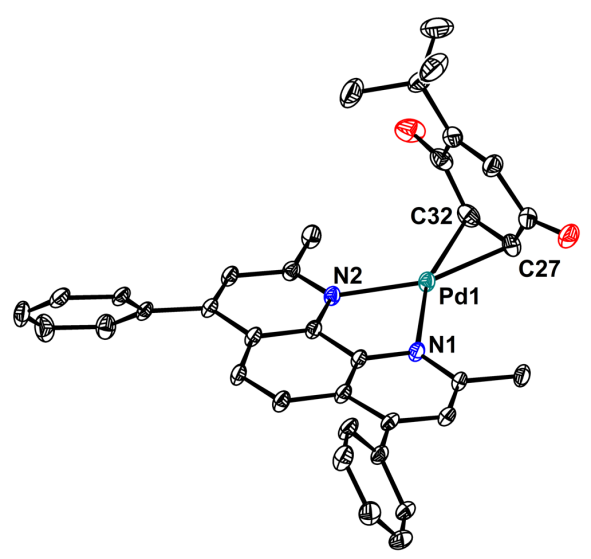

Table S11. Crystal data and structure refinement for (bc)Pd( $\left({ }^{\mathrm{BuB}} \mathrm{BQ}\right)$

Identification code Empirical formula

Formula weight stahl246 c

Temperature/K

$\mathrm{C}_{36} \mathrm{H}_{32} \mathrm{~N}_{2} \mathrm{O}_{2} \mathrm{Pd}\left(2.5 \mathrm{C}_{7} \mathrm{H}_{8}\right)$

1722.74

100

Crystal system

triclinic

Space group

$P \overline{1}$

$\mathrm{a} / \AA$

$10.619(3)$

$\mathrm{b} / \AA$

$13.727(4)$

$\mathrm{c} / \AA ̊$

$14.993(5)$

$\alpha{ }^{\circ}$

$85.713(16)$

$\beta /{ }^{\circ}$

$80.258(13)$

$\gamma /{ }^{\circ}$

$82.221(16)$

Volume $/ \AA^{3}$

2131.1(12)

Z

$\rho_{\text {calc }} \mathrm{mg} / \mathrm{mm}^{3}$

1

1.342

$\mu / \mathrm{mm}^{-1}$

0.572

$\mathrm{F}(000)$

898

Crystal size $/ \mathrm{mm}^{3}$

$0.12 \times 0.09 \times 0.01$

Radiation

$2 \Theta$ range for data collection

$\operatorname{MoK} \alpha(\lambda=0.71073)$

Index ranges

Reflections collected

2.3154 to $28.2760^{\circ}$

$-14 \leq \mathrm{h} \leq 14,-18 \leq \mathrm{k} \leq 17,-20 \leq 1 \leq 19$

Independent reflections

44651

$10640[$ Rint $=0.0439$, Rsigma $=0.0404]$

Data/restraints/parameters

$10640 / 0 / 442$

Goodness-of-fit on $\mathrm{F}^{2}$

1.077

Final $\mathrm{R}$ indexes $[\mathrm{I}>=2 \sigma(\mathrm{I})]$

Final $R$ indexes [all data]

$\mathrm{R}_{1}=0.0510, \mathrm{wR}_{2}=0.1302$

$\mathrm{R}_{1}=0.0606, \mathrm{wR}_{2}=0.1363$

Largest diff. peak/hole / e $\AA^{-3}$ 


\title{
10. Computational data
}

Computational Procedure: Geometry optimizations and frequency calculations for all reported structures were performed with the Gaussian 09 suite of programs ${ }^{6}$ at the B3LYP-D3(BJ)/[6-31G(d,p) + Lanl2dz (Pd)] level of theory with the corresponding Hay-Wadt effective core potential for Pd, and Grimme's empirical dispersion-correction (D3) with Becke-Johnson (BJ) damping for B3LYP. ${ }^{7-12}$ Frequency analysis was used to characterize each minimum with zero imaginary frequency. Bulk solvent effects were incorporated for all calculations (including the geometry optimization and frequency calculations) using the self-consistent reaction field polarizable continuum model (IEF-PCM). ${ }^{13-15}$ As a solvent we chose chloroform $(\varepsilon=4.7113)$. Calculated cartesian coordinates of all studied systems are given below.

\section{Computational Structures and Coordinates}

\author{
H2BQ \\ O $4.45305900-0.861464001 .03417100$ \\ C $4.66532500-0.534872002 .34911300$ \\ C 4.582892000 .776786002 .82801300 \\ C $4.97646700-1.571436003 .23362000$ \\ C 4.808982001 .048617004 .17658300 \\ H 4.341905001 .589793002 .14795600 \\ C $5.20255900-1.299605004 .58219000$ \\ H $5.03923800-2.586866002 .85668400$ \\ C 5.120123000 .012052005 .06109100 \\ H 4.746221002 .064048004 .55351700 \\ H 5.44355800 -2.11261100 5.26224400 \\ O 5.332399000 .338647006 .37603000 \\ H $5.53541600-0.465051006 .87337700$ \\ H $4.25001800-0.057768000 .53683000$ \\ BQ \\ O $4.71524800-0.589563001 .06285100$ \\ C $4.79725700-0.438536002 .27846700$ \\ C 4.720655000 .910214002 .89337200 \\ C $4.97578200-1.598015003 .18772000$ \\ C 4.809834001 .075203004 .22241600 \\ H 4.589758001 .742380002 .20891300 \\ C $5.06496100-1.433023004 .51676400$ \\ H $5.02904100-2.573807002 .71536500$ \\ C $4.98841800-0.084269005 .13166100$ \\ H 4.756526002 .050991004 .69477600 \\ H 5.19581100 -2.26519500 5.20122700 \\ O 5.070181000 .066735006 .34729900
}

\section{AcOH}

C - 1.683078002 .560926001 .48944900

O - 2.241740002 .595524000 .25868600

C -2.066375003 .765906002 .30582200$

$\mathrm{H}-1.595988003 .710901003 .28637900$

$\mathrm{H}-1.752452004 .678450001 .79120200$

$\mathrm{H}-3.153783003 .808928002 .41528000$

O - 0.965910001 .651381001 .85492400 
py

C - $1.86615700-1.74287100-1.61577200$

C - $1.99595100-2.77236900-2.54878700$

$\mathrm{N}-1.10495500-0.65519400-1.80864700$

C - $1.29799200-2.67139600-3.75205000$

C $-0.44030400-0.57325800-2.97070500$

C $-0.50219100-1.54692100-3.96868200$

$\mathrm{H}-1.37238000-3.45157400-4.50331900$

H $0.05951000-1.42234400-4.88838400$

H - $2.62794300-3.62753500-2.33392700$

H $0.173091000 .31467800-3.11200000$

H -2.39921100 -1.79420400 -0.66827900

bpy

C $-2.83785600-0.805836001 .80451700$

$\mathrm{N}-2.31303300-0.740002000 .57669600$

C $-2.27256800-1.87008400-0.15362100$

C $-2.74824300-3.094966000 .33784700$

C $-3.29234100-3.146258001 .61873800$

C $-3.34369900-1.976099002 .37349700$

H -3.66064700 -4.08463900 2.02114800

H $-3.75775500-1.965368003 .37586200$

C $-1.69001700-1.77404000-1.52317500$

C $-2.16083100-2.59345300-2.56007400$

$\mathrm{N}-0.70848200-0.87183700-1.71080700$

C $-1.58868400-2.48254000-3.82490100$

C $-0.16962900-0.77772500-2.93074600$

C $-0.56598700-1.55646200-4.01970300$

H - $1.94191400-3.10223200-4.64303800$

$\mathrm{H}-0.08916600-1.43319500-4.98601900$

$\mathrm{H}-2.97476600-3.28756400-2.38464100$

$\mathrm{H}-2.67247900-3.99398800-0.26289400$

H $0.62500000-0.04291300-3.04668900$

$\mathrm{H}-2.859084000 .126688002 .36557800$

\section{dmbpy}

C -2.66102000 -0.85699200 1.89520800

$\mathrm{N}-2.21104700-0.776830000 .63327800$

C $-2.19992900-1.88579600-0.12483900$

C - $2.63396400-3.129211000 .35750400$

C -3.10016800 -3.21075900 1.66612100

C -3.11806100 -2.05963000 2.44962900

H -3.43574100 -4.16009200 2.07204100

$\mathrm{H}-3.47356600-2.086974003 .47423300$

C $-1.69423700-1.74829700-1.52210500$

C - $2.22234700-2.54092300-2.55162800$

$\mathrm{N}-0.72978900-0.83762700-1.73719500$

C - $1.72067200-2.38173800-3.83987200$

C $-0.24599100-0.68676500-2.98007300$

C $-0.71570500-1.44370300-4.06144400$ 
H - $2.11424000-2.97380700-4.66033200$

H - $0.30176100-1.29242400-5.05274000$

$\mathrm{H}-3.02207500-3.24451400-2.35160800$

H - $2.58345000-4.01234600-0.26851700$

C $0.843881000 .33979000-3.15411900$

H $0.519974001 .30934300-2.76344800$

H $1.736604000 .04749000-2.59074100$

H $1.121698000 .45823500-4.20387000$

C -2.655384000 .423911002 .68974700$

$\mathrm{H}-1.651714000 .860311002 .70089200$

$\mathrm{H}-3.321727001 .161419002 .22980600$

H -2.97860200 0.260427003 .72025300

\section{dmphen}

C -3.39042900 -0.70264400 1.50794400

$\mathrm{N}-2.87969600-0.715532000 .28308100$

C $-2.32462500-1.86002000-0.18879700$

C - $-2.26863600-3.053342000 .58288500$

C - $2.81967100-3.012071001 .88462400$

C -3.37856500 -1.84491500 2.34879600

H -2.79391900 -3.90537700 2.50232200

H $-3.80811100-1.786481003 .34377300$

C $-1.76660200-1.86856400-1.53250400$

C $-1.18547800-3.06989700-2.02438300$

$\mathrm{N}-1.81964700-0.73206700-2.27142400$

C $-0.65189500-3.04483000-3.33381000$

C - $1.31254700-0.73458500-3.49785900$

C $-0.71295500-1.88547500-4.07024100$

$\mathrm{H}-0.19960900-3.94435400-3.74194700$

$\mathrm{H}-0.31123000-1.83968000-5.07739600$

C - $1.15139200-4.24835500-1.21155900$

C $-1.67409400-4.240389000 .04631000$

H $-0.69988000-5.14736200-1.62100900$

$\mathrm{H}-1.64970500-5.132779000 .66494800$

C -3.997248000 .586748001 .99702700$

$\mathrm{H}-3.477876000 .948937002 .89140600$

$\mathrm{H}-3.933498001 .348315001 .21854100$

$\mathrm{H}-5.048451000 .445433002 .27181200$

C $-1.391545000 .54631400-4.28729700$

$\mathrm{H}-1.883598001 .31961100-3.69564700$

$\mathrm{H}-0.391658000 .89590700-4.56794500$

H - $1.952547000 .39933000-5.21699500$

phen

C -3.31593200 -0.69200700 1.52916900

$\mathrm{N}-2.82278600-0.688501000 .29921000$

C $-2.30183100-1.84261600-0.18400900$

C - $2.27085400-3.042272000 .58287900$

C - $2.80619900-3.002786001 .88940500$

C -3.33287700 -1.82295400 2.37036800

H - $2.79495400-3.903335002 .49658400$

H -3.75210400 -1.75399800 3.36821800

C $-1.75506400-1.85778900-1.53366500$ 
C $-1.20895600-3.07201400-2.03951400$

$\mathrm{N}-1.78343900-0.71729100-2.26527200$

C $-0.68430700-3.06189500-3.35093700$

C - $1.28173800-0.74838900-3.49136100$

C $-0.71828100-1.89567700-4.08545900$

$\mathrm{H}-0.26132600-3.97394000-3.76217600$

H - $0.32491200-1.84938000-5.09506800$

C $-1.20030400-4.25568400-1.23026500$

C - $1.71090300-4.241347000 .03100500$

$\mathrm{H}-0.77662600-5.16421300-1.64801800$

$\mathrm{H}-1.70407600-5.137992000 .64366100$

$\mathrm{H}-3.726522000 .250746001 .88735400$

H - $1.319611000 .18419800-4.05216600$

\section{DAF}

O -7.48897300 15.2378540020 .51363700

$\mathrm{N}-5.8333340012 .2592160017 .15453700$

$\mathrm{N}-4.4334630014 .9963840016 .83908400$

C -6.5754960011 .1870190017 .50445000$

H -6.42734600 10.2927540016 .90428500

C -7.49113700 11.1673460018 .56021600

H -8.04615100 10.26045100 18.77187400

C -7.67669100 12.3226360019 .32950000

H -8.37604400 12.3547080020 .15873300

C -6.9203610013.42914600 18.97971300

C -6.8552170014 .8044820019 .56612000$

C -5.8433610015 .5325440018 .73806900$

C -5.3678100016 .8314000018 .81189600$

H -5.72870500 17.52370800 19.56567800

C -4.40230300 17.20061700 17.86723900

H -3.98119900 18.1995680017 .86024700

C -3.97708700 16.26446200 16.92050000

H -3.22766100 16.54582000 16.18491900

C -5.3483630014 .6652930017 .74400000$

C -6.0237730013 .3452690017 .89598100$

(py) ${ }_{2} \mathbf{P d}(\mathbf{A c O})_{2}$

Pd -1.99306700 $0.93453400-0.89950300$

C -1.857402002 .581807001 .44574300$

O -2.275398002 .635639000 .20563600$

C -2.12018100 3.869266002 .21304000

$\mathrm{H}-1.671775003 .817555003 .20567500$

$\mathrm{H}-1.716407004 .725635001 .66593500$

H -3.19951500 4.02424700 2.30962100

O -1.316846001 .607588001 .97184700$

O - $1.71071000-0.76655900-2.00466600$

C $-2.12748400-0.71226100-3.24517200$

O - $2.666523000 .26254000-3.77174400$

C $-1.86617800-2.00036600-4.01188500$

$\mathrm{H}-2.27945400-2.85465200-3.46853600$

$\mathrm{H}-2.30701900-1.94523500-5.00771100$

H $-0.78717000-2.16207000-4.10025200$ 
$\mathrm{N}-0.177639001 .66998400-1.56274100$

C $0.769989000 .82737200-2.01672100$

C $0.062874002 .99504200-1.54503700$

C $2.000086001 .28843100-2.47020400$

H $0.50425400-0.22208600-2.01789700$

C $1.268473003 .52391800-1.99024600$

$\mathrm{H}-0.733576003 .61184000-1.14857700$

C $2.255880002 .65899300-2.46021200$

H $2.737958000 .57802200-2.82418200$

H $1.421848004 .59640600-1.96399500$

H $3.206670003 .04566700-2.81153700$

$\mathrm{N}-3.808558000 .19904000-0.23621700$

C - $4.04955200-1.12592000-0.25517400$

C -4.755716001 .041508000 .21902400$

C -5.25515400 -1.65483100 0.18998100

H - $3.25345700-1.74258000-0.65256800$

C -5.985776000 .580406000 .67256500$

$\mathrm{H}-4.489629002 .090876000 .22111000$

C $-6.24206300-0.790052000 .66126300$

H -5.40891700 -2.72723800 0.16267700

H -6.72324400 1.290712001 .02759200

H -7.19284100 -1.17675600 1.01258700

\section{(py) ${ }_{2} \mathbf{P d}(\mathrm{BQ})$}

C -3.22359700 0.802874001 .67747500

$\mathrm{N}-2.714116000 .214483000 .57907100$

C $-2.46186500-1.107166000 .61538800$

C $-2.72233000-1.890097001 .73567000$

C $-3.26450200-1.282510002 .86775800$

C -3.515147000 .088806002 .83629600$

H -3.48170500 -1.86464200 3.75726300

H -3.92694500 0.606672003 .69518600

Pd -2.18707000 $1.46420900-1.16287600$

C $-3.79748800-0.87721300-2.56444900$

C $-4.32293700-1.64744200-3.59720000$

$\mathrm{N}-2.976691000 .16627900-2.78118800$

C $-3.98937500-1.32498300-4.91211900$

C $-2.667679000 .48626100-4.05280800$

C $-3.15005100-0.23546400-5.14097800$

H $-4.38079200-1.90622700-5.74056800$

H $-2.871354000 .06095800-6.14593300$

C $-1.194859003 .20046100-1.95489800$

C - $2.232070003 .79312300-2.79777100$

C $-1.254078003 .28936000-0.53063200$

C -3.36726000 4.45782100-2.09719200

O - $2.202726003 .75495400-4.03833400$

C -2.376007003 .966326000 .12732500$

$\mathrm{H}-0.367117003 .130056000 .07577100$

C -3.43276600 4.53481900-0.75671400

$\mathrm{H}-4.132884004 .88888300-2.73636300$

O -2.48297600 4.068849001 .35989300

$\mathrm{H}-4.255058005 .03133600-0.24892100$

H - $0.262866002 .95123700-2.45466100$ 
H -2.04228000 $1.36199300-4.19084400$ $\mathrm{H}-3.375069001 .876425001 .62425700$ $\mathrm{H}-2.50128200-2.951200001 .71390500$ $\mathrm{H}-4.98078000-2.47809200-3.36773100$ $\mathrm{H}-2.03733500-1.53867000-0.28474600$ H -4.03872500 -1.09126600 - 1.52971300

(bpy)Pd(AcO) 2 C -2.88479500 -0.69479100 1.70620400 $\mathrm{N}-2.35431000-0.780120000 .47978200$ C - $2.22668200-1.98219400-0.14138200$ C -2.63878600 -3.15070500 0.49729900 C $-3.18416300-3.071259001 .77746200$ C -3.31214000 -1.82752200 2.39248600 $\mathrm{H}-3.50784700-3.973364002 .28448600$ H $-3.73569200-1.727085003 .38440800$ Pd $-1.739706000 .82632800-0.62706900$ C - 1.262473002 .654336001 .50053000 O - 2.261527002 .181753000 .80230800 C -1.692730003 .711139002 .50919900$ H -0.835594004 .048320003 .09321400$ H -2.13860400 4.562953001 .98695400 H -2.45727000 3.303977003 .17747300 O -0.085565002 .302978001 .39044600$

O - $1.054556002 .28052200-1.87875700$

C $-1.981332002 .92376200-2.53919400$

O $-3.189917002 .68203200-2.49400800$

C $-1.64083100-1.93030900-1.49376100$

C $-1.39657700-3.04629200-2.29256500$

$\mathrm{N}-1.33084800-0.68536200-1.94215700$

C $-0.82818300-2.87068600-3.55298500$

C $-0.77584600-0.50942200-3.14792900$

C $-0.50926500-1.58609700-3.98837200$

H $-0.63422400-3.73111000-4.18360100$

H $-0.06105400-1.41183200-4.95900600$ C - $1.417055004 .02942800-3.42182000$ $\mathrm{H}-0.755410003 .59753800-4.17923300$ H -2.22552000 $4.57241600-3.91264700$ $\mathrm{H}-0.817005004 .72000900-2.82260300$ H - $1.64167700-4.03907600-1.93797600$ H $-2.54045500-4.109492000 .00471700$ $\mathrm{H}-0.549067000 .51751900-3.40873100$ H -2.96037900 0.307993002 .10980100

\section{(bpy) $)_{2} \mathbf{P d}(\mathrm{BQ})$}

C - 1.885351000 .201791001 .64709300

$\mathrm{N}-1.72584600-0.104387000 .35321600$

C $-1.83864000-1.38545000-0.06341900$

C - $2.10435600-2.409364000 .85097700$

C - $2.25805900-2.096338002 .19966100$

C $-2.15296000-0.768414002 .60954800$

H - $2.46328100-2.882400002 .91830700$ 
H -2.27498600 -0.48410000 3.64815200

Pd $-1.267882001 .39022300-1.17714800$

C - $1.68425400-1.61504000-1.52404400$

C - $1.75426400-2.88488600-2.10515800$

$\mathrm{N}-1.48117300-0.51504400-2.28682400$

C - $1.62089900-3.01381000-3.48537000$

C - $1.35810000-0.64022600-3.61472100$

C - $1.42307900-1.87259000-4.25976600$

$\mathrm{H}-1.67311200-3.99409200-3.94657800$

H - $1.31950200-1.92795200-5.33703200$

C $-0.788538003 .33072900-1.99526900$

C - $1.947981003 .66487200-2.82887200$

C $-0.874817003 .38248600-0.56933000$

C -3.21606600 3.99132900-2.11272100

O - $1.914582003 .69264400-4.06640700$

C -2.13137900 3.731429000 .10455900

H 0.022976003 .450248000 .03946400

C $-3.300391004 .02468800-0.77130400$

$\mathrm{H}-4.068559004 .22150000-2.74603300$

O -2.24918500 3.772585001 .33854900

H $-4.224126004 .28080500-0.25958800$

H $0.176540003 .36105800-2.49287900$

H - $1.206739000 .28219800-4.16492100$

$\mathrm{H}-1.803658001 .255998001 .89818700$

H -2.19620900 -3.43656900 0.52275900

H - $1.90954800-3.76506800-1.49483200$

(dmbpy)Pd(AcO) ${ }_{2}$

C $-2.50985600-0.874688001 .90622400$

$\mathrm{N}-2.19339100-0.800780000 .59651800$

C $-2.45237300-1.84970300-0.23535800$

C $-3.12873200-2.978960000 .21778800$

C $-3.51177900-3.045468001 .55448700$

C $-3.17685800-2.001843002 .40424800$

H $-4.04146000-3.914810001 .92825600$

H -3.42174400 -2.04040500 3.45902300

Pd - $1.629257000 .88063400-0.50619900$

C -1.483588003 .015517001 .36759400$

O -2.377108002 .307576000 .73701400$

C -2.08413300 4.18888500 2.12976900

H - 1.295310004 .858359002 .47532800

H -2.79334800 4.734897001 .50301300

$\mathrm{H}-2.635305003 .812150002 .99824100$

O -0.274378002 .767649001 .41173600$

O - $1.213161002 .45706800-1.72464200$

C $-2.133254002 .70016800-2.61414400$

O $-3.149094002 .02328600-2.80222500$

C $-1.88678600-1.75152000-1.59663300$

C $-2.00316800-2.76733300-2.54048900$

$\mathrm{N}-1.15270500-0.63230000-1.85432100$

C - $1.31732000-2.64885500-3.74711300$

C $-0.42561200-0.53661700-2.98500700$

C $-0.50196900-1.54687600-3.95367000$ 
H - $1.39772500-3.42618000-4.49895900$

H $0.08800700-1.44945700-4.85753500$

C - $1.838122003 .94516500-3.44140400$

$\mathrm{H}-0.828292003 .89589700-3.85851600$

$\mathrm{H}-2.567641004 .04745800-4.24567900$

$\mathrm{H}-1.880291004 .82987700-2.79839800$

$\mathrm{H}-2.60502500-3.64312100-2.34053900$

H -3.34186200 -3.80144200-0.45104600

C $0.495872000 .62822500-3.19398100$

H $0.034921001 .37698000-3.84366000$

H $0.742750001 .11407000-2.25271200$

H $1.407941000 .27748400-3.68373900$

C -2.133305000 .245266002 .82604000$

$\mathrm{H}-1.171911000 .677251002 .54498500$

H -2.87703900 1.043749002 .76973800

H - $2.08790200-0.120171003 .85363800$

\section{(dmbpy)Pd(BQ)}

C - 1.527940000 .130966001 .77070100

$\mathrm{N}-1.54408600-0.083623000 .44091800$

C $-1.96142700-1.27098500-0.05768100$

C $-2.43203500-2.281315000 .78468600$

C $-2.45377400-2.058915002 .15825000$

C $-1.98603300-0.849548002 .65830100$

H -2.81803200 -2.82957600 2.82930000

H - $1.96907500-0.654700003 .72433200$

Pd - $1.248336001 .47348800-1.10117300$

C $-1.83934300-1.45658900-1.52854400$

C $-2.21896300-2.64072300-2.16504400$

$\mathrm{N}-1.29232100-0.43292900-2.22550900$

C $-2.00743900-2.76803700-3.53473600$

C - $1.04999400-0.55762200-3.54464500$

C $-1.40398300-1.72635600-4.22893000$

H -2.29820900 -3.67817000 -4.04859000

H - $1.20371400-1.80482500-5.29122100$

C - $1.098749003 .38162400-2.05652000$

C $-2.261559003 .46919900-2.94565900$

C $-1.244432003 .56244700-0.64512300$

C -3.59339100 3.65536800-2.30535100

O $-2.182630003 .39979700-4.18109700$

C -2.56028700 $3.83861900-0.05867100$

$\mathrm{H}-0.391256003 .84244600-0.03376100$

C -3.73047600 3.82526100-0.98014400

$\mathrm{H}-4.444316003 .67426500-2.98062000$

O -2.73333400 4.08029600 1.14493600

$\mathrm{H}-4.699154003 .99007700-0.51655200$

$\mathrm{H}-0.133011003 .52112800-2.53400700$

$\mathrm{H}-2.76844200-3.228968000 .38655900$

H - 2.66695700 -3.45410800 - 1.61064900

C $-0.383106000 .58843400-4.24540600$

$\mathrm{H}-1.058119001 .44539300-4.33698200$

H $0.483970000 .92371300-3.66945200$

H $-0.056315000 .29245200-5.24465700$ 
C -0.993984001 .443490002 .26209600$

$\mathrm{H}-0.026698001 .650634001 .79527700$

$\mathrm{H}-1.661755002 .268793001 .99575300$

H - 0.870306001 .427929003 .34711000

(phen)Pd(AcO)

C -2.99163500 -0.78153700 1.63829200

$\mathrm{N}-2.45055300-0.840843000 .42632300$

C - $2.22476500-2.05240800-0.15565900$

C - $2.53139800-3.269468000 .48714200$

C -3.09890500 -3.18756300 1.77947500

C -3.32906900 -1.94859600 2.34767300

$\mathrm{H}-3.157366000 .213695002 .03415400$

H -3.35110400 -4.09801000 2.31323200

H -3.76636500 -1.85767600 3.33460900

Pd $-1.896421000 .72511100-0.79148800$

C - 1.534157002 .630264001 .28861000

O -2.493734002 .127206000 .55724600$

C -2.023728003 .715488002 .23859300$

H - 1.201058004 .076271002 .85691400

H -2.44395500 4.547601001 .66573800

H -2.82195000 3.325101002 .87667300

O -0.34999100 2.287654001 .24917700

O $-1.249422002 .12242300-2.12113900$

C $-2.190751002 .69084600-2.82818900$

O $-3.390768002 .41117800-2.77824900$

C $-1.65714000-2.05208900-1.46636200$

C $-1.38891600-3.26895500-2.12646900$

$\mathrm{N}-1.39327700-0.84015100-2.03125000$

C $-0.81892200-3.18661500-3.41767500$

C $-0.85074200-0.78061200-3.24257200$

C $-0.54993500-1.94757700-3.96838600$

$\mathrm{H}-0.59533600-4.09690300-3.96430500$

$\mathrm{H}-0.654658000 .21459300-3.62446700$

$\mathrm{H}-0.11003600-1.85652600-4.95415500$

C - $1.655816003 .76628000-3.76489800$

$\mathrm{H}-0.900675003 .34088100-4.43249300$

$\mathrm{H}-2.468276004 .19344500-4.35371200$

$\mathrm{H}-1.168422004 .55558700-3.18488700$

C $-1.70533600-4.49783100-1.45354000$

C - $2.25362400-4.49805400-0.20319200$

H $-1.49865900-5.43265900-1.96363900$

H -2.48971400 -5.43304800 0.29365000

\section{(phen)Pd(BQ)}

C - 1.849911000 .003481001 .87635600

$\mathrm{N}-1.74009400-0.123133000 .55765700$

C $-1.89519300-1.35488900-0.00047100$

C - $2.17052200-2.507826000 .77459900$

C - $2.27641500-2.342676002 .17362700$

C - $2.11676400-1.086921002 .72428800$

$\mathrm{H}-2.48478300-3.204572002 .79963600$

H -2.19480600 -0.92570400 3.79307400 
Pd - $1.268069001 .45629500-0.94067400$

C - $1.78553600-1.47562600-1.43341600$

C - $1.96567900-2.73702500-2.05019700$

$\mathrm{N}-1.52257900-0.35369800-2.15160000$

C - $1.87073300-2.79090000-3.45917500$

C - $1.45077400-0.42335900-3.47644800$

C - $1.61962400-1.63470300-4.17197100$

$\mathrm{H}-2.00242700-3.74119500-3.96699700$

H - $1.55069000-1.64414400-5.25349400$

C $-2.23774400-3.88548500-1.23413900$

C - $2.33386600-3.775215000 .12082200$

H - $2.36798400-4.84632200-1.72146300$

$\mathrm{H}-2.54110800-4.647232000 .73271200$

C - $0.713167003 .22394100-1.95631000$

C - $1.820022003 .36292800-2.91128500$

C $-0.880050003 .55140300-0.57504600$

C $-3.115811003 .85604900-2.36578200$

O $-1.716052003 .07794600-4.11366500$

C $-2.154585004 .08359000-0.08157000$

$\mathrm{H}-0.016393003 .729149000 .05921000$

C -3.26832200 4.18237200-1.07063500

H -3.92739600 $3.95023300-3.08211600$

O -2.334940004 .453339001 .08600400$

H -4.21072900 $4.55837200-0.68175600$

H $0.279334003 .14483100-2.39238600$

H - $1.265587000 .51363000-3.99548900$

H - 1.725117001 .004612002 .27496500

\section{(dmphen)Pd(AcO) $)_{2}$}

C -3.33294300 -0.67514800 1.51145400

$\mathrm{N}-2.68491700-0.689345000 .34254900$

C - $2.17273600-1.86786900-0.13535900$

C - $2.21940300-3.070712000 .60239900$

C $-2.84043900-3.024988001 .87095800$

C $-3.40694000-1.850710002 .30011600$

H $-2.88792000-3.923053002 .47827400$

H -3.92635700 -1.79826500 3.24993300

Pd $-2.023318000 .90054600-0.85646700$

C - 1.391337002 .421442001 .45439300

O - 2.274795002 .394506000 .49658700

C - 1.572741003 .613996002 .38445000

$\mathrm{H}-0.822985003 .595269003 .17609900$

$\mathrm{H}-1.486237004 .545084001 .81677800$

H -2.57432600 3.594811002 .82462300

O -0.499170001 .586871001 .63296800$

O - $1.112384002 .36050100-1.93993600$

C $-1.919733003 .19745200-2.52714400$

O $-3.144003003 .06380900-2.62275900$

C $-1.62962900-1.87192300-1.46065700$

C $-1.14889900-3.08075000-2.01164200$

$\mathrm{N}-1.65384000-0.69818300-2.16737100$

C $-0.70145100-3.04482300-3.35050300$ 
$\begin{array}{lll}\text { C }-1.28085100 & -0.68968000 & -3.45290000 \\ \text { C }-0.79042100 & -1.87156700 & -4.05996300 \\ \text { H }-0.31590400 & -3.94809300 & -3.81228700 \\ \text { H }-0.48760000 & -1.82764300 & -5.09933700 \\ \text { C }-1.19477700 & 4.37240500 & -3.16866200 \\ \text { H }-0.66312800 & 4.02399600 & -4.06087700 \\ \text { H }-1.91012300 & 5.14179400 & -3.46217700 \\ \text { H }-0.45139600 & 4.78967500 & -2.48528100 \\ \text { C }-1.15793100 & -4.27401900 & -1.22073200 \\ \text { C }-1.67399100 & -4.26912700 & 0.04080700 \\ \text { H }-0.76083900 & -5.18470100 & -1.65655200 \\ \text { H }-1.69848000 & -5.17558600 & 0.63632600 \\ \text { C }-4.01476100 & 0.56518300 & 2.00208400 \\ \text { H }-3.42767700 & 1.02412400 & 2.80457400 \\ \text { H }-4.13564900 & 1.30003100 & 1.21124900 \\ \text { H }-4.98745400 & 0.29607000 & 2.42290400 \\ \text { C }-1.38778600 & 0.56625600 & -4.25928800 \\ \text { H }-2.31099500 & 1.09949200 & -4.02701600 \\ \text { H }-0.55821000 & 1.23690900 & -4.02227700 \\ \text { H }-1.35751800 & 0.32858800 & -5.32383600\end{array}$

\section{(dmphen)Pd(BQ)}

C - 1.440151000 .062612001 .81245100

$\mathrm{N}-1.40973600-0.106009000 .48788700$

C - $1.80273400-1.29043600-0.05558600$

C $-2.29454800-2.358846000 .73260000$

C $-2.35993800-2.152763002 .12815200$

C $-1.92621500-0.959704002 .66106400$

$\mathrm{H}-2.73758200-2.943936002 .76846800$

H - $1.94862300-0.788243003 .73104100$

Pd $-1.067339001 .44680200-1.05605800$

C - $1.67431400-1.46618200-1.48265400$

C - $2.04357600-2.70309500-2.06437200$

$\mathrm{N}-1.16535700-0.43955900-2.21726000$

C $-1.85837500-2.84017000-3.45771500$

C $-0.96002900-0.59485000-3.52779700$

C $-1.31186600-1.80146600-4.17731400$

$\mathrm{H}-2.13502700-3.76993400-3.94521600$

H $-1.14245900-1.89324500-5.24394100$

C $-2.56668300-3.75256400-1.24021900$

C $-2.68735500-3.586870000 .10665900$

H $-2.85562900-4.68544800-1.71368200$

H $-3.07457000-4.384551000 .73251100$

C $-0.847378003 .35512900-1.99221800$

C - $2.009247003 .49779000-2.87585000$

C $-0.981163003 .52703800-0.57802500$

C $-3.331368003 .72430400-2.22842400$

O $-1.937262003 .44453700-4.11241100$

C - 2.283367003 .849861000 .01509600

$\mathrm{H}-0.116169003 .769291000 .03297200$

C -3.45711300 $3.88658500-0.90128800$

$\mathrm{H}-4.183280003 .78145000-2.90030000$ 
O -2.44303900 4.09235900 1.22036100

$\mathrm{H}-4.417142004 .08302500-0.43205600$ H $0.121130003 .46306300-2.47246600$

C $-0.336938000 .53929000-4.28437900$

$\mathrm{H}-1.010785001 .40015500-4.33655600$

H $0.567300000 .87645400-3.76942900$

$\mathrm{H}-0.076838000 .23371000-5.29984100$

C -0.931508001 .357016002 .37212500$

H 0.064933001 .567217001 .97241500

H - 1.572743002 .195508002 .08304200

H -0.87619200 1.314624003 .46179400

\section{(DAF)Pd(AcO) 2}

C -2.81489800 -0.819461001 .87538800$

$\mathrm{N}-2.36487400-0.639824000 .61431400$

C - $2.16837000-1.75171100-0.08622400$

C - $-2.38235000-3.062973000 .32225500$

C - $2.85350600-3.254472001 .61506800$

C -3.06412600 -2.09749400 2.38784300

$\mathrm{H}-2.957936000 .071363002 .47127100$

H -3.04976100 -4.24142800 2.01918100

H -3.42554000 -2.18243200 3.40565200

Pd $-1.825605001 .00242000-0.65327400$

C - 1.749079002 .477773001 .79285300

O -2.394889002 .429101000 .65793000$

C -2.202523003 .634382002 .67322000$

$\mathrm{H}-1.738202003 .561190003 .65721500$

H - 1.916150004 .582029002 .20667100

H -3.29122000 3.634809002 .77226400

O - 0.864788001 .694622002 .14797300

O - $1.175874002 .48523500-1.85945300$

C - $1.822030002 .65610300-2.98244800$

O - $2.754595001 .95693200-3.38602300$

C - $1.67473700-1.71484300-1.43960000$

C - $1.56371500-3.00050400-1.95617600$

$\mathrm{N}-1.39165600-0.56745800-2.04721700$

C $-1.10736300-3.12065700-3.26279900$

C $-0.95442300-0.67699400-3.32070900$

C $-0.80485300-1.92381400-3.93814400$

$\mathrm{H}-0.98963000-4.08301700-3.74852500$

$\mathrm{H}-0.740039000 .24575000-3.84184200$

$\mathrm{H}-0.44922300-1.95237900-4.96112000$

C $-2.01030800-3.95658900-0.85577100$

O $-2.05962500-5.16513100-0.90668500$

C - $1.302813003 .84460600-3.78009700$

$\mathrm{H}-0.214099003 .80155100-3.86727700$

$\mathrm{H}-1.757265003 .85744000-4.77135900$

$\mathrm{H}-1.553056004 .77210900-3.25565100$

\section{(DAF)Pd(BQ)}

C - $1.82960200-0.008304001 .90779800$

$\mathrm{N}-1.670484000 .026020000 .56610900$

C $-1.78433500-1.14701000-0.04732500$ 
C $-2.04405800-2.381312000 .55228900$

C - $2.20437600-2.415932001 .93050900$

C -2.09194300 -1.19039100 2.60806700

$\mathrm{H}-2.40818900-3.339038002 .46236000$

H -2.20869100 -1.14592300 3.68453100

Pd $-1.227886001 .57883400-1.06382400$

C - $1.65944700-1.31647900-1.49109100$

C $-1.83859300-2.65969800-1.82819000$

$\mathrm{N}-1.42020700-0.31360600-2.32814300$

C $-1.76466700-3.01020300-3.16918300$

C $-1.35326300-0.65385100-3.63417200$

C - $1.51701200-1.96939000-4.08004500$

H - $1.89347000-4.03405900-3.50327200$

H - $1.45100400-2.17431900-5.14212400$

C - $0.768826003 .43022600-1.99432100$

C - $1.907109003 .64230800-2.90233200$

C $-0.906526003 .62956900-0.58935100$

C $-3.208064004 .01687600-2.27680400$

O $-1.821554003 .52555300-4.13010000$

C -2.18955600 $4.05928400-0.01198500$

$\mathrm{H}-0.033239003 .786071000 .03786900$

C $-3.337274004 .20738800-0.95326000$

H $-4.041319004 .14793900-2.96154100$

O - 2.342648004 .299897001 .19079500

H $-4.281405004 .50196400-0.50362100$

H $0.211832003 .43008100-2.46235700$

$\mathrm{H}-1.167462000 .15691600-4.33030400$

$\mathrm{H}-1.745671000 .941267002 .42493500$

C $-2.09212600-3.42374600-0.54545600$

O $-2.29319600-4.61460200-0.42336600$

\section{$\left[\mathbf{P d}^{\mathrm{I}}(\mu-\mathrm{DAF})(\mathbf{A c O})\right]_{2}$}

Pd $-0.96475000-0.800994000 .17421400$

C $-4.04250500-0.61491800-0.39167100$

O $-5.11669300-0.73942500-0.99623700$

O -2.88727100 -0.86772400-0.92355900

Pd $1.25437700-0.780571001 .38756900$

C 3.800712000 .119837002 .69039900

O 3.258871001 .242840002 .64727800

O $3.22026300-0.997600002 .41840200$

$\mathrm{N}-0.389745000 .80343600-1.00480600$

C - $1.359296001 .67137700-1.39511000$

C $0.777423000 .87296800-1.65243900$

C $-1.195138002 .58310900-2.43264000$

H -2.29777900 $1.58841300-0.86682400$

C $0.991870001 .72696400-2.74848100$

C $0.002491002 .60406400-3.15689400$

H -2.01442300 $3.24604600-2.68309300$

N $0.27091800-0.777853003 .20936400$

C $0.83904700-0.074117004 .22448200$

C $-0.70409500-1.630167003 .53488900$

C $0.46961200-0.241158005 .55657300$

H 1.622237000 .614239003 .92332000 
C - $1.08490600-1.890786004 .86194400$

C $-0.49737200-1.192428005 .90329100$

H 0.962584000 .355774006 .31456200

H - $0.77686400-1.378371006 .93460600$

H $0.153193003 .26927500-4.00002100$

C $5.27118800-0.005014003 .08331900$

H $5.84524800-0.358004002 .21985100$

H 5.671401000 .955102003 .41271600

H $5.39155700-0.748105003 .87696400$

C -4.06351100 -0.16300200 1.07413200

$\mathrm{H}-4.04423600-1.046149001 .72232000$

H -3.19057900 0.444837001 .32898200

$\mathrm{H}-4.982011000 .388036001 .28508400$

C - $1.52083100-2.470353002 .63480200$

$\mathrm{N}-1.58329200-2.431035001 .30129000$

C $-2.31983100-3.322510003 .41547600$

C $-2.40038000-3.334014000 .69860200$

C $-3.16634400-4.233089002 .80708300$

C $-3.17608700-4.246772001 .40641100$

H - 2.45188100 -3.26645800 -0.37947600

H -3.79385300 -4.89692800 3.39158200

H $-3.80627600-4.936269000 .85791800$

C $2.010480000 .08787700-1.41848100$

C $2.930579000 .38609000-2.43895600$

N $2.29174700-0.73965800-0.40735400$

C $4.16252400-0.24300200-2.47649100$

C $3.49727300-1.36658900-0.44449800$

C $4.43039900-1.16292700-1.45599100$

H $4.88237100-0.02408200-3.25752500$

H $3.71382500-1.998146000 .40604000$

H $5.36977600-1.70123500-1.41906200$

C $-2.10436200-2.989991004 .86280400$

O -2.64281300 -3.49997900 5.82569700

C $2.349334001 .45022200-3.31849300$

O $2.867042001 .97559600-4.28480200$ 


\section{References}

1. Bakhmutov, V. I.; Berry, J. F.; Cotton, F. A.; Ibragimov, S.; Murillo, C. A. Non-Trivial Behavior of Palladium Acetate. Dalton Trans. 2005, 1989-1992.

2. Jaworski, J. N.; McCann, S. D.; Guzei, I. A.; S. S. Stahl. Detection of Pd(I) in Aerobic Oxidation Catalysis. Angew. Chem. Int. Ed. 2017, 56, 3605.

3. Sheldrick, G. M. A Short Histroy of SHELXL. Acta Cryst. 2008, A64, 112-122.

4. Dolomanov, O.V.; Bourhis, L.J.; Gildea, R.J.; Howard, J.A.K.; Puschmann, H. OLEX2: A Complete Structure Solution, Refinement and Analysis Program. J. Appl. Cryst. 2009, 42, 339-341.

5. Guzei, I. A. An Idealized Molecular Geometry Library for Refinement of Poorly Behaved Molecular Fragments with Constraints. J. Appl. Crystallogr. 2014, 47, 806-809.

6. Frisch, M. J.; Trucks, G. W.; Schlegel, H. B.; Scuseria, G. E.; Robb, M. A.; Cheeseman, J. R.; Scalmani, G.; Barone, V.; Mennucci, B.; Petersson, G. A.; Nakatsuji, H.; Caricato, M.; Li, X.; Hratchian, H. P.; Izmaylov, A. F.; Bloino, J.; Zheng, G.; Sonnenberg, J. L.; Hada, M.; Ehara, M.; Toyota, K.; Fukuda, R.; Hasegawa, J.; Ishida, M.; Nakajima, T.; Honda, Y.; Kitao, O.; Nakai, H.; Vreven, T.; Montgomery, J. A., Jr.; Peralta, J. E.; Ogliaro, F.; Bearpark, M.; Heyd, J. J.; Brothers, E.; Kudin, K. N.; Staroverov, V. N.; Kobayashi, R.; Normand, J.; Raghavachari, K.; Rendell, A.; Burant, J. C.; Iyengar, S. S.; Tomasi, J.; Cossi, M.; Rega, N.; Millam, M. J.; Klene, M.; Knox, J. E.; Cross, J. B.; Bakken, V.; Adamo, C.; Jaramillo, J.; Gomperts, R.; Stratmann, R. E.; Yazyev, O.; Austin, A. J.; Cammi, R.; Pomelli, C.; Ochterski, J. W.; Martin, R. L.; Morokuma, K.; Zakrzewski, V. G.; Voth, G. A.; Salvador, P.; Dannenberg, J. J.; Dapprich, S.; Daniels, A. D.; Farkas, Ö.; Foresman, J. B.; Ortiz, J. V.; Cioslowski, J.; Fox, D. J., Gaussian 09, Revision D.01, Gaussian, Inc., Wallingford CT, 2009.

7. Hay, P. J.; Wadt, W. R. Ab Initio Effective Core potentials for Molecular Calculations. Potentials for the Transition Metal Atoms Sc to Hg. J. Chem. Phys. 1985, 82, 270-283.

8. Wadt, W. R.; Hay, P. J. Ab Initio Effective Core Potentials for Molecular Calculations. Potentials for Main Group Elements Na to Bi. J. Chem. Phys. 1985, 82, 284-298.

9. Becke, A. D. Density-functional Exchange-energy Approximation with Correct Asymptotic Behavior. Phys. Rev. A 1988, 38, 3098-3100.

10. Lee, C.; Yang, W.; Parr, R. G. Development of the Colle-Salvetti Correlation-energy Formula into a Functional of the Electron Density. Phys. Rev. B 1988, 37, 785-789.

11. Becke, A. D. A New Mixing of Hartree-Fock and Local Density Functional Theories. J. Chem. Phys. 1993, 98, 1372-1377.

12. Grimme, S.; Antony, J.; Ehrlich, S.; Krieg, H. A Consistent and Accurate Ab Initio Parametrization of Density Functional Dispersion Correction (DFT-D) for the 94 Elements H-Pu. J. Chem. Phys. 2010, 132, 154104.

13. Cancès, E.; Mennucci, B.; Tomasi, J. A New Integral Equation Formalism for the Polarizable Continuum Model: Theoretical Background and Applications to Isotropic and Anisotropic Dielectrics. J. Chem. Phys. 1997, 107, 3032-3041.

14. Mennucci, B.; Tomasi, J. Continuum Solvation Models: A New Approach to the Problem of Solute's Charge Distribution and Cavity Boundaries. J. Chem. Phys. 1997, 106, 5151-5158.

15. Scalmani, G.; Frisch, M. J. Continuous Surface Charge Polarizable Continuum Models of Solvation. I. General Formalism. J. Chem. Phys. 2010, 132, 114110. 